\title{
Dynamic General Equilibrium and T-Period Fund Separation
}

\author{
Anke Gerber, Thorsten Hens, and Peter Woehrmann*
}

\begin{abstract}
In a dynamic general equilibrium model, we derive conditions for a mutual fund separation property by which the savings decision is separated from the asset allocation decision. With logarithmic utility functions, this separation holds for any heterogeneity in discount factors, while the generalization to constant relative risk aversion holds only for homogeneous discount factors but allows for any heterogeneity in endowments. The logarithmic case provides a general equilibrium foundation for the growth-optimal portfolio literature. Both cases yield equilibrium asset pricing formulas that allow for investor heterogeneity, in which the return process is endogenous and asset prices are determined by expected discounted relative dividends. Our results have simple asset pricing implications for the time series as well as the cross section of relative asset prices. It is found that on data from the Dow Jones Industrial Average, a risk aversion smaller than in the logarithmic case fits best.
\end{abstract}

\section{Introduction}

Ever since Tobin (1958), financial economists have been interested in conditions that help to simplify portfolio allocation problems. A great simplification is achieved by those conditions that allow portfolio decisions to be structured into the following two stages: first, deciding how to split one's wealth between a riskfree and a mutual fund of risky assets, and then allocating among the risky assets within the mutual fund. This property is known as two-fund separation, or more specifically, as monetary separation, since one of the funds is assumed to be risk

\footnotetext{
*Gerber, anke.gerber@wiso.uni-hamburg.de, University of Hamburg, Department of Economics, Von-Melle-Park 5, 20146 Hamburg, Germany; Hens, thens@isb.uzh.ch, Swiss Finance Institute and Swiss Banking Institute, Plattenstr. 32, CH-8032 Zurich, Switzerland and Norwegian School of Economics and Business Administration, Helleveien 30, 5042 Bergen, Norway; and Woehrmann, pwoehrmann@ethz.ch, Swiss Federal Institute of Technology Zurich, KPL F 38.2, Kreuzplatz 5, 8032 Zurich, Switzerland. We thank an anonymous referee, Stephen Brown (the editor), Mathias Hoffmann, and Karl Schmedders for helpful comments. Gerber was at the University of Zurich at the time the paper was written. Woehrmann did part of the work at the University of Zurich and greatly acknowledges financial support from the Ecoscentia Foundation. Financial support by the National Centre of Competence in Research in "Financial Valuation and Risk Management" is also gratefully acknowledged. The national centers in research are managed by the Swiss National Science Foundation on behalf of the federal authorities.
} 
free. The conditions for two-fund separation are well known. The seminal paper in this area is Cass and Stiglitz (1970), out of which an impressive literature developed, too large to be reviewed here. Instead, we refer the reader to Russell (1980) and standard textbooks such as Gollier (2001), Huang and Litzenberger (1988), Ingersoll (1987), and Magill and Quinzii (1996). While the finance literature on two-fund separation considers asset returns as exogenously given, the general equilibrium literature derives two-fund separation with endogenously determined returns. For example, Detemple and Gottardi (1998) obtain two-fund separation in a two-period general equilibrium model, and Judd, Kubler, and Schmedders (2006) have recently extended the two-fund separation literature to dynamic general equilibrium models.

In this paper, we use the dynamic general equilibrium methodology of Judd et al. (2006). However, we are interested in a new separation property that simplifies intertemporal asset allocation problems by separating between consumption and investments in (risky) assets. We call this separation property T-period fund separation, since in all $T$-periods there is one mutual fund that is identical for all agents. One may argue that this separation is even more fundamental than monetary separation, because before one can decide on how to allocate wealth among (risky) assets, one must decide how much to invest and how much to consume.

As in Cass and Stiglitz (1970), Detemple and Gottardi (1998), Judd et al. (2006), and others, we do not restrict return distributions but seek out conditions on agents' preferences and asset endowments to obtain $T$-period fund separation. Moreover, as is standard in the literature, we assume that all agents are discounted expected utility maximizers sharing the same beliefs about the assets' returns. Given these assumptions, conditions for fund separation must restrict the heterogeneity of the agents' risk aversion and possibly also the heterogeneity of their discount rates. Our first result shows that $T$-period fund separation holds for any heterogeneity in discount factors if all agents have logarithmic utility functions and collinear endowments. In the general case of equi-cautious constant relative risk aversion (CRRA) different from 1, $T$-period fund separation is shown to hold if and only if agents' discount factors are identical. In this case, however, any degree of heterogeneity in the endowments is allowed. These results generalize Hens, Reimann, and Vogt (2004) to more than two periods. The intuition for our results is as follows: Under CRRA, changes in wealth do not influence the asset allocation. Moreover, since agents have either logarithmic preferences, and hence are myopic, or else have identical time preferences, on the same investment opportunities, they will hold the same portfolios of risky assets. Finally, given these portfolio choices, fluctuations in asset prices result only from the exogenous dividend process. Hence, agents choose fixed-mix portfolio strategies whenever expected relative dividends are constant. We proceed to show that the assumptions we make are tight; that is, in contrast to the two-period case, with $T$-periods the fund separation we consider fails for nonunit CRRA with heterogeneous discount factors. The reason for this result is that, except for the case of logarithmic utility, dynamic optimization introduces additional heterogeneity. The special role of logarithmic utility for dynamic optimization was first noted by Hakansson (1970). 
In addition to describing the conditions for intertemporal fund separation, our results are of interest because they relate to various strands of the literature. Our findings for the logarithmic case give a general equilibrium foundation to the literature on growth-optimal portfolios. See, for example, Kelly (1956), Breiman (1961), Thorp (1971), Algoet and Cover (1988), Hakansson and Ziemba (1995), and references therein. These authors have praised the growth-optimal portfolio from an individual investor's point of view. However, if an investor achieves a higher growth rate than other investors, eventually there will be general equilibrium effects (i.e., investors whose wealth grows more rapidly will determine equilibrium prices). In our model, all general equilibrium effects are accounted for since asset prices, and hence market values and returns, are endogenized and ultimately explained by the exogenous dividend process of the assets. Hence, our finding that under stationarity assumptions on the relative dividend process, all agents play a "fixed-mix" portfolio rule provides a general equilibrium foundation to the literature on fixed-mix portfolio rules (see, e.g., Perold and Sharpe (1988), Ziemba and Mulvey (1998), Browne (1998), Dempster (2002), and Dempster, Germano, Medova, and Villaverde (2003)).

Our result for the logarithmic case also relates nicely to the asset pricing literature, which is one of the most important applications of fund separation. From a dynamic general equilibrium point of view, the art of constructing asset pricing models consists of finding an optimal balance between very general models without well-structured preferences and a large degree of heterogeneity on the one hand, and very specific models with overly simplified preferences and consumer homogeneity on the other. In the former case, anything can happen, while in the latter, asset pricing puzzles arise. Fund separation is an important tool in this respect, since it allows for heterogeneity of consumers while keeping the aggregate simple. Indeed, two-fund separation builds the foundation of the two-period capital asset pricing model (CAPM) and, accordingly, $T$-period fund separation is important for the time-series and cross-section properties of relative asset prices. Our result shows that in a dynamic general equilibrium, relative market values of assets are determined by the relative dividends of those assets. Valuation formulas for economies with CRRA utility are established in the finance literature (see, e.g., Roll (1973), Kraus and Litzenberger (1975), and Rubinstein (1976)). Note, however, that in contrast to the standard partial equilibrium point of view, our valuation formulas take all feedback effects into account and are expressed solely in terms of such exogenous characteristics of the economy as the dividend process, the degree of risk aversion, and the time preference.

While our asset pricing implication for logarithmic preferences has recently also been derived by Evstigneev, Hens, and Schenk-Hoppé (2006) based on an evolutionary portfolio selection model, our result for the case of nonlogarithmic utility generalizes this asset pricing implication to any degree of CRRA. This generalization allows us to test the log versus the nonlog CRRA case on stock market data. For quarterly data (1992-2004) on dividends and market values of stocks from the Dow Jones Industrial Average, we find that a coefficient of relative risk aversion around 0.57 fits best (i.e., asset prices suggest a smaller degree of risk aversion than in the logarithmic case $($ CRRA $=1)$ ). This finding contrasts with the asset pricing literature, which works with aggregate data rather than individual 
stocks and which finds a much larger degree of risk aversion than in the logarithmic case (cf. Mehra and Prescott (1985), Kocherlakota (1996), for example). This difference arises because we do not explain the equity premium puzzle (i.e., the relative advantage of equity over risk-free investments), but rather the ratio of asset returns among risky assets.

In particular, our empirical results show that relative dividends have some predictive power for asset returns. The importance of dividends for asset pricing has been documented many times in the literature. Considering a present value model with a stochastic discount factor, Hagiwara and Herce (1997) demonstrate that the variance bounds are better met when discount factors are evaluated with observed dividends rather than with consumption. The intuition behind this result is that dividends reveal more variability than aggregate consumption. Moreover, there is empirical evidence that multifactor models with dividend yields have improved on the CAPM in explaining the cross section of stock returns (see, e.g., Jagannathan and Wang (1996), Cochrane (1996)). Therefore, expected stock returns carry a risk premium for the dividend yield. It has also been found in pooled and cross-sectional studies that the dividend yield has a direct impact on stock returns (see, e.g., Litzenberger and Ramaswamy (1979), (1980)). It can been shown asymptotically (i.e., for many assets) that this implies a proportional relationship between relative dividends and expected future instances of relative prices. Also, the return predictability of dividend yields has been analyzed extensively in the literature. The results are mixed. Black and Scholes (1974) find "no obvious connection between dividend yields and returns." However, subsequent papers find that dividend yields do have predictive power for future stock returns. Keim (1985) finds that the link between dividend yields and returns is associated with the "January effect." Fama and French (1988) find that the predictive power of dividend yields increases with the time horizon. Campbell and Shiller (1988) look at dividend yields over time rather than cross-sectionally. On the more skeptical side, Goetzmann and Jorion (1995) argue that at least part of the predictability found in previous studies is due to survivorship bias. Wolf (2000) also finds little evidence for stock return predictability. Our result shows the importance of relative dividends for stock returns. In a study combining relative dividends and dividend yields, Spare and Ciotti (1999) show that simple strategies based on relative dividend yields give attractive returns. An interesting paper by Dimson and Marsh (2000) connects relative dividend growth with the size premium. But as far as we are aware, there is no empirical study of relative dividends.

Finally, we show that our heterogeneous agent economy can be described equivalently by a single representative consumer whose demand function determines equilibrium asset prices for any exogenously given future dividend process. This aggregation property is weaker than the demand aggregation of Rubinstein (1976), according to which the aggregate excess demand function of the economy can be derived from the decision problem of a single representative consumer. However, the aggregation property we derive is far stronger than the usual notion of a representative consumer in the sense of Constantinides (1982). As Welch and Goyal (2008) have recently emphasized, this notion of a representative consumer has an in-sample-out-of-sample problem: The portfolio decision problem of the representative consumer generates asset prices for any given dividend process, but 
the optimization problem fails to explain how asset prices change with changes in the exogenous characteristics of the economy (here, the dividend process). In our case, this problem does not arise, since the aggregation we derive also works out-of-sample (i.e., for any other dividend process).

Since demand aggregation in the two-period model is closely related to Pareto efficiency and linear sharing rules, we point out the differences between these properties in the $T$-period model. In contrast to the two-period model, the assumptions for deriving linear sharing rules (e.g., hyperbolic absolute risk aversion (HARA) utilities) are no longer sufficient for $T$-period fund separation.

This paper proceeds as follows. In Section II, we set up the dynamic general equilibrium model. Section III provides an analysis of $T$-period fund separation under CRRA, and Section IV presents results from an empirical test of our model. Finally, Section V presents our conclusion.

\section{The Model}

We consider a standard multiperiod finance economy with $T+1$ periods (dates) $t=0, \ldots, T$. In all periods $t<T$, investors can trade in $K$ long-lived assets, which pay dividends at the beginning of every period. ${ }^{1}$ The asset market is competitive (i.e., all investors take asset prices as given when choosing their optimal portfolio). Asset prices are endogenous and determined by market clearing.

In the remainder of this section, we present our model in detail. In the following section, we derive conditions under which investors hold the same portfolio of assets in equilibrium. As our analysis will show, the equilibrium portfolio and market prices are essentially determined by expected relative dividends.

\section{A. Uncertainty and Information}

The model we present here is the so-called event-tree model. The reader familiar with such a framework may skip this paragraph.

There are $S$ states of nature, where $S$ is finite. Each $s \in\{1, \ldots, S\}$ denotes a path the economy can follow over $T+1$ periods. Uncertainty is modeled by an information filtration

$$
\mathcal{F}=\left(F_{0}, F_{1}, \ldots, F_{T}\right)
$$

where each $F_{t}$ is a partition of the set of states $\{1, \ldots, S\}$. Any $\xi_{t} \in F_{t}$ is an observable event at date $t$, which we call a date- $t$-event. Hence, $F_{t}$ embodies the information about the state of nature available at date $t$. We make the following assumptions on our information filtration $\mathcal{F}$ :
i) $F_{0}=\{\{1, \ldots, S\}\}$,
ii) $F_{T}=\{\{1\}, \ldots,\{S\}\}$,

\footnotetext{
${ }^{1}$ Since there is asset trade in all but the last period, we call the model a " $T$-period model."
} 
iii) $F_{t+1}$ is finer than $F_{t}$ for all $t=0, \ldots, T-1$, that is,

$$
\xi_{t} \in F_{t} \quad \text { and } \quad \xi_{t+1} \in F_{t+1} \quad \Rightarrow \quad \xi_{t+1} \subset \xi_{t} \quad \text { or } \quad \xi_{t+1} \cap \xi_{t}=\emptyset .
$$

By conditions i) and ii), there is no information about the state of nature at date 0 and full information at date $T$. Moreover, by virtue of condition iii), information increases over time (i.e., everything that is known at date $t$ is also known at any future date $t^{\prime}>t$ ). This condition implies that for any date- $t$-event $\xi_{t} \in F_{t}$, and for any $0 \leq \tau<t$, there exists a unique date- $\tau$-event $\xi_{\tau} \in F_{\tau}$ with $\xi_{\tau} \supset \xi_{t}$. Here, $\xi_{\tau}$ is called the predecessor of $\xi_{t}$ at date $\tau$.

Let $\pi\left(\xi_{T}\right)>0$ be the probability of $\xi_{T} \in F_{T}$. Then, for all $t=0, \ldots, T, \pi$ defines a probability measure on $F_{t}$, which we also denote by $\pi$, via

$$
\pi\left(\xi_{t}\right)=\sum_{\xi_{T} \subset \xi_{t}} \pi\left(\xi_{T}\right) .
$$

Let $d$ be the total number of events. ${ }^{2}$ Then, for $x \in \mathbb{R}^{d}$ and any $t \in\{0, \ldots, T\}$, we denote by $x_{t}$ the vector in $\mathbb{R}^{\# F_{t}}$ that takes values $x\left(\xi_{t}\right), \xi_{t} \in F_{t}{ }^{3}$

\section{B. Assets}

There are $K$ assets $k=1, \ldots, K$, which pay off a nonnegative dividend per share at the beginning of every period before trade commences in this period. Dividend payments depend on the realized event in the given period. Here, $D^{k}(\xi) \geq 0$ denotes the dividend paid by asset $k$ and $D(\xi)=\left(D^{1}(\xi), \ldots, D^{K}(\xi)\right)$ denotes the vector of dividend payments of all assets in event $\xi$. We assume that aggregate dividends are strictly positive, that is,

$$
\bar{D}(\xi):=\sum_{k=1}^{K} D^{k}(\xi)>0, \quad \text { for all } \xi .
$$

We do not impose any further restrictions on $K$ and $\left(D^{k}\right)_{k}$. In particular, we allow for $K$ to be smaller than the number of immediate successors $\xi_{t+1}$ of any date- $t$ event $\xi_{t} \supset \xi_{t+1}$. Hence, the financial market may be incomplete and there may be redundant assets.

As will become clear, equilibrium prices and portfolios in our model are essentially determined by relative dividends. For $\eta>0$, we define the $\eta$-adjusted relative dividend of asset $k$ by

$$
\frac{D^{k}}{(\bar{D})^{\eta}}
$$

For $\eta=1$, we obtain the relative dividend of asset $k$, which we denote by $d^{k}$, that is,

$$
d^{k}:=\frac{D^{k}}{\bar{D}}
$$

\footnotetext{
${ }^{2} d=\#\left\{\xi \mid \xi \in F_{t}\right.$ for some $\left.t \in\{0, \ldots, T\}\right\}$.

${ }^{3}$ Alternatively, we can interpret $x_{t}$ as an $F_{t}$-measurable function $x_{t}:\{1, \ldots, S\} \rightarrow \mathbb{R}$ (i.e., $x_{t}(s)=$ $x_{t}\left(s^{\prime}\right)$ whenever $s, s^{\prime} \in \xi_{t}$ for some $\left.\xi_{t} \in F_{t}\right)$.
} 


\section{Investors}

There are $I$ investors, $i=1, \ldots, I$. Investor $i$ has an initial portfolio of assets $\bar{\theta}^{i} \in \mathbb{R}^{K}, \bar{\theta}^{i}>0$. Without loss of generality we normalize the aggregate endowment $\bar{\theta}=\sum_{i} \bar{\theta}^{i}$ such that $\bar{\theta}_{k}=1$ for all $k$. Each investor $i$ has a discounted expected utility function $U^{i}: \mathbb{R}_{+}^{d} \rightarrow \mathbb{R}$, respectively $U^{i}: \mathbb{R}_{++}^{d} \rightarrow \mathbb{R}$, given by

$$
U^{i}(c)=\sum_{t=0}^{T} \beta_{i}^{t} \mathrm{E}\left[u^{i}\left(c_{t}\right)\right], \quad \text { for all } c \in \mathbb{R}_{+}^{d} \quad\left(\text { respectively, } c \in \mathbb{R}_{++}^{d}\right),
$$

where $0<\beta_{i}<1$ is $i$ 's discount factor and $u^{i}: \mathbb{R}_{+} \rightarrow \mathbb{R}$ (respectively, $u^{i}: \mathbb{R}_{++} \rightarrow$ $\mathbb{R})$ is $i$ 's von Neumann and Morgenstern (1944) utility function. Here, E[·] denotes the expectation with respect to the probability measure $\pi .^{4}$

We assume that all investors have CRRA $\eta>0$, that is, investor $i$ 's von Neumann and Morgenstern (1944) utility function $u^{i}: \mathbb{R}_{+} \rightarrow \mathbb{R}$ (respectively, $\left.u^{i}: \mathbb{R}_{++} \rightarrow \mathbb{R}\right)$ is given by

$$
u^{i}(c)= \begin{cases}\frac{1}{1-\eta} c^{1-\eta}, & \eta \neq 1 \\ \ln (c) & , \quad \eta=1\end{cases}
$$

\section{Asset Trade and Wealth Dynamics}

In each nonterminal event, investors can trade in the $K$ assets. Let $q^{k}(\xi)>0$ denote the price of asset $k$ in event $\xi$. Note that due to our normalization of the asset supply $\left(\bar{\theta}_{k}=1\right), q^{k}(\xi)$ is the market capitalization of asset $k$. It is convenient to define $q^{k}\left(\xi_{T}\right):=0$ for all terminal events $\xi_{T} \in F_{T}$ and all $k$.

For each nonterminal event $\xi$, let $\lambda_{k}^{i}(\xi) \in \mathbb{R}$ be the proportion of wealth that agent $i$ invests in asset $k \in\{1, \ldots, K\}$ in event $\xi$, and let $\lambda_{0}^{i}(\xi)$ denote the proportion of wealth that $i$ consumes in $\xi$. Hence, if $w^{i}(\xi)$ is investor $i$ 's wealth in event $\xi$, then she holds $\lambda_{k}^{i}(\xi) w^{i}(\xi) / q^{k}(\xi)$ units of asset $k$ and she consumes $\lambda_{0}^{i}(\xi) w^{i}(\xi)$. The investment strategy of agent $i$ is given by $\lambda^{i}=\left(\lambda_{k}^{i}(\xi)\right)_{\xi, k}$. Observe that we do not impose any short sale restrictions. However, we will see that there are no short sales in equilibrium.

Given her investment strategy $\lambda^{i}$, investor $i$ 's wealth dynamics $\left(w^{i}(\xi)\right)_{\xi}$ are as follows. ${ }^{5}$ At $t=0, w_{0}^{i}:=w^{i}\left(\xi_{0}\right)=\left(D_{0}+q_{0}\right) \bar{\theta}^{i}$, and for all $\xi_{t+1} \in F_{t+1}$ and $t=0, \ldots, T-1$,

$$
\begin{aligned}
w^{i}\left(\xi_{t+1}\right) & =w^{i}\left(\xi_{t}\right) \sum_{k=1}^{K} \frac{D^{k}\left(\xi_{t+1}\right)+q^{k}\left(\xi_{t+1}\right)}{q^{k}\left(\xi_{t}\right)} \lambda_{k}^{i}\left(\xi_{t}\right), \\
& =\cdots
\end{aligned}
$$

\footnotetext{
${ }^{4}$ Hence, we assume that all investors have homogenous and correct beliefs about the states of nature.

${ }^{5}$ In order to simplify the notation, we do not explicitly write $w^{i}$ as a function of the investment strategy $\lambda^{i}$ and asset prices $q$.
} 


$$
=w_{0}^{i} \prod_{\tau=0}^{t}\left[\sum_{k=1}^{K} \frac{D^{k}\left(\xi_{\tau+1}\right)+q^{k}\left(\xi_{\tau+1}\right)}{q^{k}\left(\xi_{\tau}\right)} \lambda_{k}^{i}\left(\xi_{\tau}\right)\right],
$$

where $\xi_{\tau}$ is the unique predecessor of $\xi_{t+1}$ at date $\tau$.

\section{T-Period Fund Separation}

In the following, we derive the portfolio and asset pricing implications for the finance economy introduced above. For given asset prices $q$, investors choose their investment strategies so as to maximize their discounted expected utility from consumption. Investor $i$ 's consumption $c^{i} \in \mathbb{R}_{+}^{d}$ is a function of her investment strategy $\lambda^{i}$ and asset prices $q$ and is given by

$$
c^{i}\left(\lambda^{i}, q\right)\left(\xi_{t}\right)=\lambda_{0}^{i}\left(\xi_{t}\right) w^{i}\left(\xi_{t}\right),
$$

for all $\xi_{t} \in F_{t}$ and for all $t=0, \ldots, T$, where $w^{i}$ is defined in expression (1) and $\lambda_{0}^{i}\left(\xi_{T}\right):=1$ for all terminal events $\xi_{T} \in F_{T}$. For given asset prices $q$, investor $i$ solves

$$
\begin{aligned}
\max _{\lambda^{i}} U^{i}\left(c^{i}\right), \quad \text { s.t. } \quad c^{i} & =c^{i}\left(\lambda^{i}, q\right), \\
\sum_{k=0}^{K} \lambda_{t k}^{i} & \leq 1, \quad \text { for all } t=0, \ldots, T-1,
\end{aligned}
$$

where, as defined previously, $\lambda_{t k}^{i}$ denotes the vector in $\mathbb{R}^{\# F_{t}}$ that takes values $\lambda_{k}^{i}\left(\xi_{t}\right)$ for $\xi_{t} \in F_{t}$.

Since $U^{i}$ is strictly increasing, the optimal investment strategy satisfies $\sum_{k=0}^{K}$ $\lambda_{t k}^{i}=1$ for all $t=0, \ldots, T-1$. Moreover, by strict concavity of $U^{i}$, any solution $\lambda^{i}$ to expression (2) induces the same interior consumption $c^{i}{ }^{6}$ The first-order condition for a solution to expression (2) is given by

$$
q_{t}^{k}=\sum_{\tau=t+1}^{T} \beta_{i}^{\tau-t} \mathrm{E}_{t}\left[\left(\frac{c_{t}^{i}}{c_{\tau}^{i}}\right)^{\eta} \frac{c_{\tau}^{i}}{c_{t+1}^{i}} \lambda_{t+1,0}^{i}\left(D_{t+1}^{k}+q_{t+1}^{k}\right)\right],
$$

for all $t=0, \ldots, T-1$ and all $k=1, \ldots, K$, where $\mathrm{E}_{t}[\cdot]$ denotes the expectation conditional on the sigma-algebra induced by the partition $F_{t}$ (see the Appendix for a derivation of equation (3)). Given the properties of $U^{i}$, equation (3) is necessary and sufficient for a solution to expression (2).

Since assets are in unit supply, market clearing requires that the assets' market capitalizations are given by

$$
q_{t}^{k}=\sum_{i=1}^{I} \lambda_{t k}^{i} w_{t}^{i}
$$

for all $k=1, \ldots, K$, and for all $t=0, \ldots, T-1$. A competitive equilibrium then is defined by optimization and market clearing.

\footnotetext{
${ }^{6}$ Since we did not rule out redundant assets, several investment strategies may induce the same consumption.
} 
Definition 1. A profile of investment strategies $\lambda=\left(\lambda^{i}\right)_{i}$ together with asset prices $q$ is a competitive equilibrium, if

i) Optimization. $U^{i}\left(c^{i}\left(\lambda^{i}, q\right)\right) \geq U^{i}\left(c^{i}\left(\tilde{\lambda}^{i}, q\right)\right)$ for all investment strategies $\tilde{\lambda}^{i}$ and all $i=1, \ldots, I$, and

ii) Market Clearing. $q_{t}^{k}=\sum_{i=1}^{I} \lambda_{t k}^{i} w_{t}^{i}$ for all $k=1, \ldots, K$, and for all $t=$ $0, \ldots, T-1$.

If in equilibrium all investors hold the same portfolio of assets, we say that the equilibrium has the $T$-period fund separation property.

Definition 2. A competitive equilibrium $(\lambda, q)$ is an equilibrium with T-period fund separation, if there exists $\left(\bar{\lambda}_{t k}\right)_{\substack{k=1, \ldots, K \\ t=0, \ldots, T-1}}$ with $\sum_{k=1}^{K} \bar{\lambda}_{t k}=1$, for all $t=0, \ldots$, $T-1$, such that for all $i$,

$$
\lambda_{t k}^{i}=\left(1-\lambda_{t 0}^{i}\right) \bar{\lambda}_{t k}, \quad \text { for all } k=1, \ldots, K
$$

Hence in an equilibrium with $T$-period fund separation, the proportion of nonconsumed wealth invested into any asset $k$ is the same across all investors. In this case, an investor's portfolio allocation problem is greatly simplified, since she only has to decide on the allocation of wealth between consumption and investment in the mutual fund. For the static case $(T=1)$, Hens et al. (2004) have shown that fund separation holds whenever all investors have the same CRRA $\eta$. For log utility $(\eta=1)$ and collinear endowments, this result generalizes to the case $T>1$.

Theorem 1. Assume that all investors have CRRA $\eta=1$, and that asset endowments are collinear, that is, $\bar{\theta}^{i}=\delta^{i} \bar{\theta}$ for all $i$, where $\delta^{i}>0$ for all $i$ and $\sum_{i} \delta^{i}=1$. Then there exists an equilibrium with $T$-period fund separation $(\lambda, q)$, which is given by

$$
\begin{aligned}
\lambda_{t 0}^{i} & =\frac{1-\beta_{i}}{1-\beta_{i}^{T+1-t}} \\
\bar{\lambda}_{t k} & =\frac{1}{\sum_{j}\left(\frac{\beta_{j}^{t+1}-\beta_{j}^{T+1}}{1-\beta_{j}^{T+1}} \delta^{j}\right)} \sum_{\tau=t+1}^{T}\left(\sum_{j} \frac{\beta_{j}^{\tau}-\beta_{j}^{\tau+1}}{1-\beta_{j}^{T+1}} \delta^{j}\right) \mathrm{E}_{t}\left[d_{\tau}^{k}\right]
\end{aligned}
$$

for all $t=0, \ldots, T-1$, for all $k=1, \ldots, K$, and for all $i$. Equilibrium prices $q$ are given by

$$
q_{t}^{k}=\bar{D}_{t} \frac{1}{\sum_{j}\left(\frac{\beta_{j}^{t}-\beta_{j}^{t+1}}{1-\beta_{j}^{T+1}} \delta^{j}\right)} \sum_{\tau=t+1}^{T}\left(\sum_{j} \frac{\beta_{j}^{\tau}-\beta_{j}^{\tau+1}}{1-\beta_{j}^{T+1}} \delta^{j}\right) \mathrm{E}_{t}\left[d_{\tau}^{k}\right],
$$

for all $k=1, \ldots, K$, and all $t=0, \ldots, T-1$. This is the unique equilibrium with the $T$-period fund separation property. 
The proof, given in the Appendix, is constructive: We suppose that all agents satisfy $T$-period fund separation such that asset allocations are determined by expected relative dividends. Then we show that this property is inherited by asset prices. Finally, we show that with those asset prices, all agents will indeed satisfy $T$-period fund separation. This proof leaves open two questions: Are there equilibria without the $T$-period fund separation property, and if not, what is the driving force behind equilibria with $T$-period fund separation? Accordingly, we present conditions for uniqueness of equilibria in the following text, and we relate $T$ period fund separation to the property of linear sharing rules. The latter is derived from Pareto efficiency and is known to be sufficient for two-fund separation in static models. As we will argue below, this is not true for dynamic models and for $T$-period fund separation. $T$-period fund separation is a property derived from the demand functions for assets - not from Pareto efficiency. We show below that $T$-period fund separation implies Pareto efficiency, but that the converse is not true.

By Theorem 1, under logarithmic utility and collinear endowments, the proportion of wealth each agent invests into an asset is given by a weighted sum of the expected future relative dividend paid by that asset. The significance of relative dividends in asset pricing was also recently demonstrated by Evstigneev et al. (2006) in an evolutionary model of portfolio selection. As shown in that paper, the unique evolutionary stable investment strategy is such that assets are evaluated by expected relative dividends. While Evstigneev et al. (2006) assume that all investors have the same consumption rate, we obtain heterogeneous consumption rates in equilibrium. As expected, consumption rates increase over time and with the agent's impatience: The smaller an agent's discount factor, the higher the proportion of wealth she consumes in each period.

From Theorem 1 it follows that there exists a unique price vector and a unique consumption allocation that is supportable by an equilibrium with $T$ period fund separation. Obviously, if there are redundant assets, then the equilibrium consumption allocation can also be supported by other (in fact, a continuum of) investment profiles, where investors do not necessarily hold identical portfolios. Hence, in this case we can interpret the $T$-period fund separation property as a simple equilibrium selection mechanism, where all agents choose the same investment strategy.

If all investors have the same time preference, the equilibrium price vector is unique (i.e., the equilibrium with $T$-period fund separation is the only equilibrium of the economy) up to the potential nonuniqueness of investment strategies discussed previously.

\section{Theorem 2. Let all investors have CRRA $\eta$, and let $\beta_{i}=\beta$ for all $i$. Then there exists a unique equilibrium price vector $q$.}

Proof. Since all investors have identical homothetic utility functions, there is full demand aggregation, that is, there exists a representative investor whose demand at any price vector $q$ is given by the aggregate demand of the agents in the economy at $q$ (cf. Antonelli (1886)). In particular, $q$ is an equilibrium price vector in the heterogeneous agent economy if and only if $q$ is an equilibrium price vector in the representative agent economy. It is straightforward to see that the utility 
function of the representative investor can be chosen to be identical to the common utility function of investors in the economy. By strict monotonicity and strict concavity of the utility function, the equilibrium price vector in the representative agent economy is unique.

Consider the case where expected relative dividends of all assets are eventand time-independent. In this particular case, Theorem 1 implies that all agents use the same stationary investment strategy. That is, in each period $t$ the proportion of wealth invested into any asset $k$ is the same, independent of the event at $t$ and thus independent of the investor's wealth that is realized in $t$. This "fixed-mix" strategy is a generalization of Kelly's (1956) "rule of betting" to multiple assets, as Evstigneev, Hens, and Schenk-Hoppé (2008) have shown.

Corollary 1 (Fixed-Mix for CRRA = 1). Under the conditions of Theorem 1, if the conditional expected relative dividends of all assets are event- and timeindependent, that is, if there exists a constant $d^{k}$ such that

$$
\mathrm{E}_{t}\left[d_{t+1}^{k}\right] \equiv d^{k}
$$

for all $k=1, \ldots, K$, and all $t=0, \ldots, T-1$, then

$$
\bar{\lambda}_{t k}=d^{k}
$$

for all $k=1, \ldots, K$ and all $t=0, \ldots, T-1$.

If all investors have the same time preference, then $T$-period fund separation holds for all coefficients of relative risk aversion $\eta$ and arbitrary, though not necessarily collinear, asset endowments. In this case, the proportion of wealth invested into an asset is given by a weighted sum of the future expected $\eta$-adjusted relative dividends of that asset.

Theorem 3. If all investors have equi-cautious CRRA $\eta$ and the same discount factor (i.e., $\beta_{i}=\beta$, for all $i$ ), then there exists an equilibrium with $T$-period fund separation $(\lambda, q)$, which is given by

$$
\begin{aligned}
\lambda_{t 0} & =\frac{\left(\bar{D}_{t}\right)^{1-\eta}}{\left(\bar{D}_{t}\right)^{1-\eta}+\sum_{\tau=t+1}^{T} \beta^{\tau-t} \mathrm{E}_{t}\left[\left(\bar{D}_{\tau}\right)^{1-\eta}\right]}, \\
\bar{\lambda}_{t k} & =\frac{\sum_{\tau=t+1}^{T} \beta^{\tau-t} \mathrm{E}_{t}\left[\frac{D_{\tau}^{k}}{\left(\bar{D}_{\tau}\right)^{\eta}}\right]}{\sum_{\tau=t+1}^{T} \beta^{\tau-t} \mathrm{E}_{t}\left[\left(\bar{D}_{\tau}\right)^{1-\eta}\right]}
\end{aligned}
$$

for all $t=0, \ldots, T-1$, and for all $k=1, \ldots, K$. Equilibrium prices $q$ are given by

$$
q_{t}^{k}=\left(\bar{D}_{t}\right)^{\eta} \sum_{\tau=t+1}^{T} \beta^{\tau-t} \mathrm{E}_{t}\left[\frac{D_{\tau}^{k}}{\left(\bar{D}_{\tau}\right)^{\eta}}\right],
$$

for all $k=1, \ldots, K$, and all $t=0, \ldots, T-1$. This is the unique equilibrium with $T$-period fund separation, and there exists no equilibrium $(\hat{\lambda}, \hat{q})$ such that $\hat{q} \neq q$. 
The proof can again be found in the Appendix. This follows the same approach as that of Theorem 1. By Theorem 3, the fund separation result of Hens et al. (2004) carries over to multiple periods for all coefficients of relative risk aversion $\eta$ if investors have the same time preference. While Theorem 1 has shown that the same holds for heterogeneous time preference and log utility, the following example demonstrates that in general there is no fund separation if $T>1$ and investors have heterogeneous time preference and nonunit CRRA utility. What makes the log utility case special is the well-known fact that investors are myopic, that is, they behave like investors with a two-period horizon (cf. Samuelson (1969)). By contrast, investors with nonunit CRRA utility are farsighted. Thus, it is not surprising that heterogeneous discount factors destroy the fund separation property in case of nonunit CRRA whenever $T>1$.

Example 1. Let $I=K=T=2$ and let dividends be given by

$$
\begin{aligned}
D^{1}\left(\xi_{0}\right)=D^{2}\left(\xi_{0}\right) & =0.5 \\
D^{1}\left(\xi_{u}\right) & =D^{2}\left(\xi_{d}\right)=1 \\
D^{1}\left(\xi_{d}\right) & =D^{2}\left(\xi_{u}\right)=0 \\
D^{1}\left(\xi_{u u}\right) & =D^{1}\left(\xi_{d u}\right)=D^{2}\left(\xi_{u d}\right)=D^{2}\left(\xi_{d d}\right)=1, \\
D^{1}\left(\xi_{u d}\right) & =D^{1}\left(\xi_{d d}\right)=D^{2}\left(\xi_{d u}\right)=D^{2}\left(\xi_{u u}\right)=0,
\end{aligned}
$$

where $\xi_{0}=\{u u, u d, d u, d d\}, \xi_{u}=\{u u, u d\}, \xi_{d}=\{d u, d d\}, \xi_{u u}=\{u u\}, \xi_{u d}=\{u d\}$, $\xi_{d u}=\{d u\}, \xi_{d d}=\{d d\}, F_{0}=\left\{\xi_{0}\right\}, F_{1}=\left\{\xi_{u}, \xi_{d}\right\}$, and $F_{2}=\left\{\xi_{u u}, \xi_{u d}, \xi_{d u}, \xi_{d d}\right\}$. Let

$$
\begin{array}{lll}
\pi\left(\xi_{u u}\right)=p_{1} p_{2}, & \pi\left(\xi_{u d}\right)=p_{1}\left(1-p_{2}\right), \\
\pi\left(\xi_{d u}\right)=\left(1-p_{1}\right) p_{2}, & \pi\left(\xi_{d d}\right)=\left(1-p_{1}\right)\left(1-p_{2}\right),
\end{array}
$$

where $0<p_{1}<1$ and $0<p_{2}<1$. If $p_{1} \neq p_{2}$, that is, if the dividends are not identically distributed over time, then there does not exist an equilibrium with $T$ period fund separation. To see this, consider the case where $p_{1}=0.9$ and $p_{2}=0.1$ and let $\eta=2$, and $\beta_{1}=0.1, \beta_{2}=0.9$. Moreover, assume that asset endowments are collinear with $\delta^{1}=\delta^{2}=0.5$. Assume by way of contradiction that there exists an equilibrium with $T$-period fund separation, and let $\lambda^{i}$ be agent $i$ 's investment strategy in this equilibrium. Then, for $k=1,2$, there exists $\bar{\lambda}_{0 k}$ such that $\lambda_{0 k}^{i}=$ $\left(1-\lambda_{00}^{i}\right) \bar{\lambda}_{0 k}$ for $i=1,2$. Substituting this into the first-order condition (3) for agent $i=1$ and solving for $\lambda^{1}$ (using the market-clearing condition), we obtain the numeric solution $\bar{\lambda}_{01} \approx 0.52$. However, solving agent 2 's first-order condition gives $\bar{\lambda}_{01} \approx 0.41$, which is a contradiction. Hence, in this example there does not exist an equilibrium with $T$-period fund separation.

Obviously, we cannot relax the assumption that all investors have CRRA utility functions. If, for example, an investor's utility function belongs to the HARA class, then from the static case we know that the investment into the riskless asset is wealth dependent unless the investor has CRRA utility (cf. Cass and Stiglitz (1970)). ${ }^{7}$ Therefore, if in some period two investors differ with respect to their wealth, they choose different portfolios of riskless and risky assets, and hence the $T$-period fund separation property does not hold.

\footnotetext{
${ }^{7}$ By contrast, the portfolio of risky assets does not depend on wealth.
} 
Similarly to the case of log utility, one obtains a fixed-mix strategy in equilibrium if dividends satisfy a particular stationarity requirement and investors have the same coefficient of relative risk aversion $\eta$. This is a simple corollary of Theorem 3 .

Corollary 2 (Fixed-Mix for Identical Discount Factors). Under the conditions of Theorem 3 , if there exists a constant $d^{k}$ such that

$$
\frac{\mathrm{E}_{t}\left[\frac{D_{t+1}^{k}}{\left(\bar{D}_{t+1}\right)^{\eta}}\right]}{\mathrm{E}_{t}\left[\left(\bar{D}_{t+1}\right)^{1-\eta}\right]} \equiv d^{k},
$$

for all $k=1, \ldots, K$, and all $t=0, \ldots, T-1$, then

$$
\bar{\lambda}_{t k}=d^{k}
$$

for all $k=1, \ldots, K$ and all $t=0, \ldots, T-1$.

A particular case, where the conditions imposed on dividends in Corollaries 1 and 2 are satisfied, is that in which the dividend process is independent and identically distributed (i.i.d.). Corollaries 1 and 2 show that a basic insight from portfolio choice theory, namely, that CRRA implies a fixed-mix investment strategy (Merton (1971)), carries over to the case where asset returns are determined endogenously. This result is not self-evident, since asset returns need not be stationary in equilibrium, ${ }^{8}$ and hence it is not obvious that a fixed-mix strategy is optimal as it is in the case of exogenous asset returns.

From the static two-period case it is well known that equilibrium allocations are Pareto efficient if the riskless asset and investor endowments lie in the asset span and if all investors have HARA utility functions and each investor's risk tolerance has the same slope. This result follows from the fact that the consumption sharing rules are affine linear in a Pareto-efficient allocation. Hence, any equilibrium allocation is Pareto efficient since it is constrained Pareto efficient and any Pareto-efficient allocation lies in the asset span. Below, we argue that this result does not necessarily carry over to the multiperiod case. First we show that the static result on affine linear consumption sharing rules still holds if there are more than two periods $(T>1)$.

Theorem 4. Let all agents have linear risk tolerance (HARA utility) with common slope, that is,

$$
-\frac{u^{i \prime}(x)}{u^{i \prime \prime}(x)}=a_{i}+b x
$$

for some constants $a_{i} \in \mathbb{R}_{+}$and $b \in \mathbb{R}$ and all $i=1, \ldots, I$. If $\left(c^{i}\right)_{i}$ is a Paretoefficient allocation, then for all $i$ there exist $\left(\alpha_{t}^{i}\right)_{t},\left(\gamma_{t}^{i}\right)_{t}$, where $\alpha_{t}^{i}$ and $\gamma_{t}^{i}$ do not depend on the event $\xi_{t}$ at date $t$ and $\sum_{i} \alpha_{t}^{i}=0, \sum_{i} \gamma_{t}^{i}=1$ for all $t$, such that

$$
c_{t}^{i}=\alpha_{t}^{i}+\gamma_{t}^{i} \bar{D}_{t}, \quad t=0, \ldots, T .
$$

\footnotetext{
${ }^{8}$ This is due to the fact that aggregate dividends $\bar{D}_{t}$, which enter asset prices, need not be stationary under the conditions of Corollaries 1 and 2.
} 
If $a_{i}=0$ for all $i$ (CRRA utility), then $\alpha_{t}^{i}=0$ for all $i$ (i.e., there is linear sharing in any Pareto-efficient allocation). If, in addition, all agents have the same discount factor $\left(\beta_{i}=\beta\right.$ for all $\left.i\right)$, then $\gamma_{t}^{i}=\gamma^{i}$ is independent of $t$ and hence for all $i$,

$$
c_{t}^{i}=\gamma^{i} \bar{D}_{t}, \quad t=0, \ldots, T .
$$

The proof is provided in the Appendix. By Theorem 4, in the case of CRRA utility, the consumption sharing rule is linear and any Pareto-efficient allocation lies in the asset span. Nevertheless, as we have seen in Example 1, an equilibrium with $T$-period fund separation does not necessarily exist if investors have nonunit CRRA utility functions and heterogeneous time preference. In Example 1 we have $a_{i}=0$ for $i=1,2$, and hence for any Pareto-efficient allocation $c$ there exist $\gamma_{t}^{i}, t=0, \ldots, T, i=1,2$, such that $c_{t}^{i}=\gamma_{t}^{i} \bar{D}_{t}$, for all $t=0, \ldots, T$, and all $i=1,2$. For an interior Pareto-efficient allocation $c$ we can use the proof of Theorem 4 to compute the investors' consumption shares as follows:

$$
\gamma_{t}^{1}=\left(1+\sqrt{\frac{\mu^{2}}{\mu^{1}} 9^{t}}\right)^{-1} \quad \text { and } \quad \gamma_{t}^{2}=\sqrt{\frac{\mu^{2}}{\mu^{1}} 9^{t}}\left(1+\sqrt{\frac{\mu^{2}}{\mu^{1}}} 9^{t}\right)^{-1}
$$

for all $t=0, \ldots, T$, where $\mu^{1}>0$ and $\mu^{2}>0$ are constant. Hence, the consumption share of the relatively more patient investor $2\left(\beta_{2}=0.9\right)$ converges to 1 for $t \rightarrow \infty$, while the consumption share of the impatient investor $1\left(\beta_{1}=0.1\right)$ converges to 0 for $t \rightarrow \infty$.

From Example 1 we conclude that a linear consumption sharing rule is not sufficient for the existence of an equilibrium with $T$-period fund separation if $T>1$. Moreover, equilibrium consumption allocations are not necessarily Pareto efficient in case of nonunit CRRA. However, in an equilibrium with $T$-period fund separation as characterized above, the corresponding consumption allocation is always efficient.

Theorem 5 (Effective Completeness). The consumption allocation $\left(c^{* i}\right)_{i}$ corresponding to the equilibrium with $T$-period fund separation $\left(\lambda^{*}, q^{*}\right)$ in Theorems 1 and 3 is Pareto efficient.

The proof, given in the Appendix, is a simple computation showing that all agents' utility gradients are collinear at the consumption allocation corresponding to the equilibrium with $T$-period fund separation. Effective completeness of the asset market implies the existence of a representative investor whose portfolio decision problem generates the equilibrium asset prices for the heterogeneous agent economy.

Theorem 6 (Representative Agent Equilibrium). Assume that the conditions of Theorem 1 , respectively Theorem 3 , are satisfied and let $\left(\lambda^{*}, q^{*}\right)$ be the corresponding equilibrium with $T$-period fund separation. Then there exists a representative investor with expected utility function $\hat{U}: \mathbb{R}_{++}^{d} \rightarrow \mathbb{R}$, respectively $\hat{U}: \mathbb{R}_{+}^{d} \rightarrow$ $\mathbb{R}$, and endowment $\bar{e} \in \mathbb{R}_{++}^{d}$, where $\bar{e}_{t}=\bar{D}_{t}$ for all $t=0, \ldots, T$, such that equilibrium asset prices in the representative agent economy are given by $q^{*}$.

If investors in the heterogeneous agent economy have CRRA $\eta$, then $\hat{U}$ can be chosen to have expected utility form with the same CRRA $\eta$. Moreover, $\hat{U}$ is independent of the future dividend process $\left(D_{t}\right)_{t=1, \ldots, T}$. 
Out of equilibrium, the demand function of the representative agent is equal to the aggregate demand in the heterogeneous agent economy if investors have the same time preference (see the proof of Theorem 2). By Theorem 6, under heterogeneous time preference we have a weaker form of demand aggregation, where the demand function of the representative agent determines equilibrium asset prices for any given future dividend process. Hence, we have demand aggregation in a sense that is most relevant to asset pricing theory.

\section{Empirical Results}

In this section, we provide an empirical test of the theoretical results derived above. In particular, we test whether market prices, in fact, can be explained by relative dividends as is predicted by the $T$-period fund separation model developed in the previous section. The main goal of our empirical analysis is to estimate the consumers' coefficient of risk aversion, as derived in Theorem 3, which can be seen as a representative consumer's coefficient of risk aversion according to Theorem 6. Interestingly, our estimated coefficient is much closer to the risk aversion observed in experimental studies (which is below 1) than to the risk aversion found in tests of Lucas's (1978) asset pricing model (which has been shown for different data frequencies to be at least 10). ${ }^{9}$

\section{A. The Econometric Hypothesis}

We want to estimate the structural parameters of the rational dynamic asset pricing model with $T$-period fund separation developed in the previous section. To this end, recall Theorem 3, which characterizes an equilibrium with $T$-period fund separation. If all investors have equi-cautious CRRA $\eta$ and the same discount factor, that is, $\beta_{i}=\beta$ for all $i$, then there exists an equilibrium with $T$-period fund separation $(\lambda, q)$, which is given by

$$
\begin{aligned}
\lambda_{t 0} & =\frac{\left(\bar{D}_{t}\right)^{1-\eta}}{\left(\bar{D}_{t}\right)^{1-\eta}+\sum_{\tau=t+1}^{T} \beta^{\tau-t} \mathrm{E}_{t}\left[\left(\bar{D}_{\tau}\right)^{1-\eta}\right]}, \\
\bar{\lambda}_{t k} & =\frac{\sum_{\tau=t+1}^{T} \beta^{\tau-t} \mathrm{E}_{t}\left[\frac{D_{\tau}^{k}}{\left(\bar{D}_{\tau}\right)^{\eta}}\right]}{\sum_{\tau=t+1}^{T} \beta^{\tau-t} \mathrm{E}_{t}\left[\left(\bar{D}_{\tau}\right)^{1-\eta}\right]}
\end{aligned}
$$

for all time periods $t=0, \ldots, T-1$, and for all assets $k=1, \ldots, K$. Recall that aggregate dividends in period $t$ are denoted by

$$
\bar{D}_{t}:=\sum_{k=1}^{K} D_{t}^{k}>0,
$$

\footnotetext{
${ }^{9}$ See, for instance, Kocherlakota (1996).
} 
that $\lambda_{t 0}$ denotes the fraction of wealth consumed in $t$, and that $\bar{\lambda}_{t k}$ is the proportion of nonconsumed wealth invested into asset $k$. Equilibrium prices $q$ are given by

$$
q_{t}^{k}=\left(\bar{D}_{t}\right)^{\eta} \sum_{\tau=t+1}^{T} \beta^{\tau-t} \mathrm{E}_{t}\left[\frac{D_{\tau}^{k}}{\left(\bar{D}_{\tau}\right)^{\eta}}\right],
$$

for all $k=1, \ldots, K$, and all $t=0, \ldots, T-1$. This is the unique equilibrium with $T$-period fund separation, and there exists no equilibrium $(\hat{\lambda}, \hat{q})$ such that $\hat{q} \neq q$.

In that model, deep parameters $\theta=(\beta, \eta)$ have to be estimated based on data. The logarithmic case provides a general equilibrium foundation for the growthoptimal portfolio literature. Thus, we will also test the hypothesis $H_{0}: \quad \eta=1$. Subsequently, we describe the data we use to estimate that hypothesis, present an adequate estimation methodology, and discuss the empirical results.

\section{B. The Data}

To estimate the asset pricing model with $T$-period fund separation, we need stock prices and dividend payments of individual stocks. It is more difficult to collect dividend data of good quality than accurate stock price data. Top-tier databases archive dividend data since 1992. To have a sufficient database, we have decided to take dividends at the highest possible frequency, which is quarterly, paid on the stocks of the companies listed in Table 1. Among the 100 largest stocks with respect to market capitalization in 2004, we have chosen those from the First Call database that provide a complete history since 1992. The respective stock prices are taken from the Center for Research in Security Prices (CRSP) database.

\section{TABLE 1}

\section{Summary Statistics for Relative Dividends}

JB and ADF denote the Jarque-Bera (1987) test for normality (null: normal distribution) and the augmented Dickey-Fuller (1979) test for unit roots (null: random walk), respectively. The data range from March 31, 1992 to June 30, 2004 and are quarterly.

\begin{tabular}{|c|c|c|c|c|c|c|}
\hline \multirow[b]{2}{*}{ Company } & \multirow[b]{2}{*}{ Mean } & \multirow{2}{*}{$\begin{array}{l}\text { Std. } \\
\text { Dev. }\end{array}$} & \multirow[b]{2}{*}{ Skewness } & \multirow[b]{2}{*}{ Kurtosis } & \multicolumn{2}{|c|}{$p$-Value } \\
\hline & & & & & $\mathrm{JB}$ & ADF \\
\hline $3 \mathrm{M}$ & 0.1320 & 0.0527 & 1.0383 & 3.5838 & 0.0079 & 0.5222 \\
\hline Altria & 0.0832 & 0.0357 & 1.3748 & 5.2152 & 0.0000 & 0.4904 \\
\hline American Express & 0.0275 & 0.0099 & 0.4960 & 2.2252 & 0.1920 & 0.2609 \\
\hline Bank of New York & 0.0225 & 0.0105 & 0.7649 & 2.7828 & 0.0831 & 0.0013 \\
\hline General Electric & 0.0162 & 0.0082 & 1.4912 & 6.2053 & 0.0000 & 0.3815 \\
\hline General Motors & 0.2442 & 0.1416 & 0.5259 & 2.4241 & 0.2236 & 0.0924 \\
\hline Hewlett Packard & 0.0216 & 0.0104 & 0.1991 & 1.7377 & 0.1612 & 0.8243 \\
\hline Intel & 0.0092 & 0.0079 & 2.0340 & 8.0703 & 0.0000 & 0.0925 \\
\hline IBM & 0.1148 & 0.0637 & -0.0605 & 2.0475 & 0.3828 & 0.7228 \\
\hline J.P. Morgan Chase & 0.0551 & 0.0162 & 0.0284 & 2.2113 & 0.5213 & 0.5807 \\
\hline Johnson \& Johnson & 0.0335 & 0.0169 & 1.0705 & 3.0277 & 0.0084 & 0.2015 \\
\hline McDonalds & 0.0190 & 0.0058 & 0.0588 & 2.1375 & 0.4542 & 0.3722 \\
\hline Merrill Lynch & 0.0429 & 0.0261 & 0.6716 & 2.6040 & 0.1297 & 0.3116 \\
\hline Microsoft & 0.0071 & 0.0057 & 0.2325 & 1.5908 & 0.1009 & 0.5072 \\
\hline Pfizer & 0.0137 & 0.0096 & 0.6306 & 2.1112 & 0.0838 & 0.1695 \\
\hline United Technologies & 0.0756 & 0.0415 & 0.6990 & 2.1477 & 0.0613 & 0.1880 \\
\hline Wachovia & 0.0819 & 0.0352 & 0.3440 & 2.5655 & 0.5018 & 0.4982 \\
\hline
\end{tabular}

A key novelty of our theoretical model is that it explains stock market prices by $\eta$-adjusted relative dividends, $D^{k} / \bar{D}^{\eta}$. We report basic summary statistics for 
relative dividends $d^{k}=D^{k} / \bar{D}$ in Table $1 .^{10}$ We cannot reject the hypothesis that relative dividends contain unit roots. The results obtained from the Jarque-Bera (1987) test for normality are mixed.

This property of the data makes it doubtful that standard estimation procedures such as generalized method of moments (GMM) will work well. Furthermore, due to the discounting of all future relative dividends, the econometric hypothesis cannot easily be written as moment conditions to be estimated by GMM. As a solution, we therefore estimate the model in the econometric hypothesis using an estimation method that builds on Den Haan and Marcet (1990) and that was first put forward in Lettau, Semmler, and Woehrmann (2007).

\section{Estimation of Nonlinear Dynamic General Equilibrium Models}

We apply an estimation procedure for dynamic optimization problems based on first-order conditions of the following form:

$$
z_{t}=\mathrm{E}_{t}\left[f\left(z_{t+1}, z_{t+2}, \ldots ; \theta\right)\right]
$$

where $z_{t}$ is a vector of state and control variables and $\theta$ refers to the structural (deep) parameters of the economic model. To solve dynamic optimization problems numerically, Den Haan and Marcet (1990) suggest parameterizing expectations by a linear or preferably nonlinear function $\psi$, which depends on a parameter vector $\omega$ and the partition of the states of nature $F_{t}$, that is,

(5) $\mathrm{E}_{t}\left[f\left(z_{t+1}, z_{t+2}, \ldots ; \theta\right)\right]=\mathrm{E}\left[f\left(z_{t+1}, z_{t+2}, \ldots ; \theta\right) \mid F_{t}\right]=\psi\left(F_{t} ; \omega\right) .{ }^{11}$

Hence, determining expectations given the trajectories of $z$ is a stochastic approximation problem,

$$
\min _{\omega} \Sigma(z, \omega)=\|f(z ; \theta)-\psi(F ; \omega)\|
$$

where $\|\cdot\|$ denotes the Euclidean norm, which is calculated in data samples as mean squared error. The solution to the dynamic problem (4) based on parameterized expectations (5) and (6) is the vector $\bar{\omega}$ satisfying $\omega^{(i)}=\omega^{(i-1)}=\bar{\omega}$ for large $i$, where $\omega^{(i)}$ is defined iteratively as follows: Let $\omega^{(0)}$ be an arbitrary starting point. For $i \geq 1$, let

$$
\begin{aligned}
\omega^{(i)} & =(1-\nu) \omega^{(i-1)}+\nu \operatorname{argmin}_{\omega} \Sigma\left(z_{t+1}, z_{t+2}, \ldots, \omega\right) \quad \text { and } \\
z_{t} & =\psi\left(F_{t} ; \bar{\omega}\right),
\end{aligned}
$$

where $\nu \in(0,1]$ describes the rate of convergence. Den Haan and Marcet (1990) find numerically that convergence is reached in models such as the neoclassical

\footnotetext{
${ }^{10}$ Note, that those results do not change qualitatively for $\eta$-adjusted relative dividends in case of realistic values for $\eta$.

${ }^{11}$ The dimension of the vector $\omega$ equals the number of parameters in the function chosen to specify $\psi$.
} 
growth model. To justify numerical convergence, we suggest that the $p$-value be associated with the null hypothesis $H_{0}: \omega^{(i)}=\omega^{(i-1)}$. This iteration describes local convergence. However, Den Haan and Marcet (1990) claim that transversality conditions or the assumption of time-invariant solutions may ensure a unique solution in the above iterative map.

We assume that empirical asset prices are generated by the solution to the above iterative map. Thus, we estimate the structural parameters by choosing $\theta$, such that the parameterized expectations (5) imply a time series for $z$ that is closest to the empirical observation of $z \cdot{ }^{12}$ Formally, we estimate the structural parameters $\hat{\theta}$ as

$$
\hat{\theta}=\operatorname{argmin}_{\theta}\|z-\psi(F ; \hat{\omega})\|, \quad \text { s.t. } \quad \hat{\omega}=\operatorname{argmin}_{\omega} \Sigma(z, \omega),
$$

$\hat{\theta}$ can be found by grid search, while the adequate algorithm for determining $\hat{\omega}$ is given by the concrete functional form of $\psi(\cdot)$. In Lettau et al. (2007), it is shown by simulation of the neoclassical stochastic growth model of Kydland and Prescott (1982) that this inferential approach applied to dynamic models reveals a small bias in small samples.

\section{Estimating the T-Period Fund Separation Model}

Now we are well equipped to test the econometric hypothesis in the first paragraph of this section. Deep parameters $\theta=(\beta, \eta)$ are estimated. The filtration $F_{t}$ is generated by $d_{t}^{k}$ and $\bar{\lambda}_{t k}$. Applying the inference scheme described above to the first-order conditions of our dynamic model provided in Theorem 3, we solve ${ }^{13}$

$$
\begin{aligned}
\hat{\theta}= & \operatorname{argmin}_{\theta} \sum_{t=0}^{T}\left\|q_{t}-\hat{q}_{t}\right\|, \\
\text { s.t. } \quad \hat{q}_{t}^{k}= & \bar{\lambda}_{t k}\left(\bar{D}_{t}\right)^{\eta} \sum_{\tau=t+1}^{T} \beta^{\tau-t}\left(\bar{D}_{t}\right)^{1-\eta}, \\
\bar{\lambda}_{t k}= & \frac{1}{\sum_{\tau=t+1}^{T} \beta^{\tau-t}\left(\bar{D}_{t}\right)^{1-\eta}} \sum_{\tau=t+1}^{T} \beta^{\tau-t} \psi\left(d_{t}^{k}, \bar{\lambda}_{t k} ; \hat{\omega}\right), \\
\psi\left(d_{t}^{k}, \bar{\lambda}_{t k} ; \omega\right)= & \omega_{1}+\omega_{2} d_{t}^{k}+\omega_{3} \bar{\lambda}_{t k}+\omega_{4}\left(d_{t}^{k}\right)^{2}+\omega_{5} d_{t}^{k} \bar{\lambda}_{t k}+\omega_{6}\left(\bar{\lambda}_{t k}\right)^{2} \\
& +\omega_{7}\left(d_{t}^{k}\right)^{3}+\omega_{8}\left(d_{t}^{k}\right)^{2} \bar{\lambda}_{t k}+\omega_{9} d_{t}^{k}\left(\bar{\lambda}_{t k}\right)^{2}+\omega_{10}\left(\bar{\lambda}_{t k}\right)^{3}, \\
\hat{\omega}= & \operatorname{argmin}_{\omega} \|\left(\bar{D}_{\tau}\right)^{1-\eta}\left(\lambda_{t+1,0} d_{t+1}^{k}+\left(1-\lambda_{t+1,0}\right) \bar{\lambda}_{t+1, k}\right) \\
& -\psi\left(d_{t} ; \omega\right) \|,
\end{aligned}
$$

\footnotetext{
${ }^{12}$ That is, we do not calibrate the model by solving it numerically.

${ }^{13}$ Note that in this specification the filtration does not contain a lagged independent variable.
} 


$$
\lambda_{t 0}=\frac{\bar{D}_{t}^{1-\eta}}{\bar{D}_{t}^{1-\eta}+\sum_{\tau=t+1}^{T} \beta^{\tau-t}\left(\bar{D}_{t}\right)^{1-\eta}} .
$$

Note that $q_{t}=\left(q_{t}^{1}, \ldots, q_{t}^{K}\right)$ and $\hat{q}_{t}=\left(\hat{q}_{t}^{1}, \ldots, \hat{q}_{t}^{K}\right)$ denote observed and estimated prices, respectively. We use the grid search technique to estimate the structural parameters. The discount factor, $\beta$, and the coefficient of risk aversion, $\eta$, are suspected to be in the interval $[0.8,1)$ and $[0.1,40]$, respectively. Here, $\psi(\cdot)$ represents a third-order polynomial function. We will also use a second-order polynomial by setting $\omega_{7}=\omega_{8}=\omega_{9}=\omega_{10}=0$. The parameters $\omega$ are determined by ordinary least squares (OLS) regression.

Results for the estimation of model parameters $\beta$ and $\eta$ with $K=17$ stocks as listed in Table 1 for $T=49$ quarterly data points, ranging from March 31, 1992 to June 30, 2004, are reported in Table 2. We find that a coefficient of relative risk aversion around 0.550 and a discount factor of 0.985 fit best $^{14}$ (i.e., asset prices would suggest a weaker degree of risk aversion than in the logarithmic case, that is $\eta=1$ ). This result is robust with respect to the degree of the polynomial chosen in the estimation procedure. The null hypothesis $H_{0}: \eta=1$ can be rejected with low $p$-values of the Wald test. ${ }^{15}$

TABLE 2

Estimation Results of the Structural Parameters

The degree of polynomial refers to the functional approximation of conditional expectations in Theorem 3 as discussed above. The null hypothesis of the Wald test is $H_{0}: \eta=1$. RMSE stands for the root mean squared error.

\begin{tabular}{lcccc} 
Polynomial & $\hat{\beta}$ & $\hat{\eta}$ & $\frac{\text { RMSE }}{2}$ & Wald $p$-Value \\
\cline { 2 - 4 } Second order & 0.985 & 0.556 & 4.213 & $4.2 \mathrm{E}-04$ \\
Third order & 0.985 & 0.552 & 4.042 & $7.6 \mathrm{E}-04$ \\
\hline
\end{tabular}

Finally, we conduct a sensitivity analysis of $\hat{\eta}$ by using various time periods for the estimation. The results in Figure 1 indicate that the risk aversion is estimated quite robustly around 0.5 , although relative dividends are nonstationary. This finding contrasts with the asset pricing literature, which uses consumption to evaluate the stochastic discount factor (see, e.g., Mehra and Prescott (1985), Kocherlakota (1996)). This literature finds a much larger degree of risk aversion, because aggregate consumption is too smooth. However, here we focus on stock prices explained by relative dividends rather than considering the equity premium puzzle. In Table 3, we evaluate the performance of the estimation results. The explained variation in individual stock returns is no worse than the explanation of the successful attempts at solving the equity premium puzzle by Campbell and Cochrane (1999) or Barberis and Huang (2001).

\footnotetext{
${ }^{14}$ Regarding the estimation horizon, the 3-month LIBOR was, on average, $4.33 \%$, suggesting that a discount factor of 0.985 is reasonable.

${ }^{15}$ Given that $\hat{\eta} \sim \mathcal{N}(\eta, \sigma), \sigma>0$, results of asymptotic theory give us $(\hat{\eta}-1)^{2} / \hat{\sigma}^{2} \sim F(1$, $T-1)$, which leads directly to a $t$-test for the hypothesis $\eta=1$, frequently termed the Wald test. Here, $\hat{\sigma}$ is obtained by omitting each data point once.
} 
FIGURE 1

Sensitivity Analysis of $\hat{\eta}$

In Figure 1, the line shows estimations $\hat{\eta}$ with respect to selected intervals of 10 years in our data.

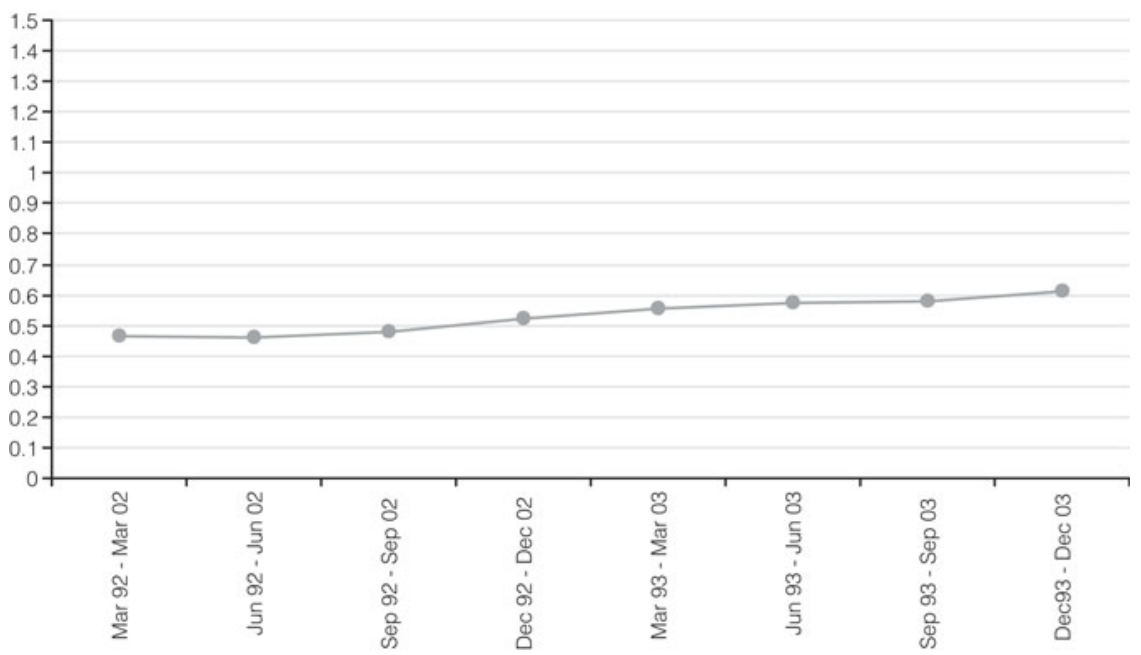

TABLE 3

Goodness-of-Fit of the Estimation

The $R^{2}$ for stock returns forecasted by the estimated model of Theorem 3 based on second-order polynomials. Due to the finite horizon, we have omitted the last three quarters.

\begin{tabular}{l}
\multicolumn{1}{c}{ Company } \\
\hline 3M \\
Altria \\
American Express \\
Bank of New York \\
General Electric \\
General Motors \\
Hewlett Packard \\
Intel \\
IBM \\
J.P. Morgan Chase \\
Johnson \& Johnson \\
McDonalds \\
Merrill Lynch \\
Microsoft \\
Pfizer \\
United Technologies \\
Wachovia
\end{tabular}

\begin{tabular}{l}
$R^{2}$ \\
\hline 0.5337 \\
0.6736 \\
0.5765 \\
0.7195 \\
0.3642 \\
0.6873 \\
0.7612 \\
0.7868 \\
0.7740 \\
0.8226 \\
0.1922 \\
0.3039 \\
0.5885 \\
0.7751 \\
0.1444 \\
0.5984 \\
0.8583
\end{tabular}

\section{Conclusion}

It is well known that general equilibrium models can generate any given arbitrage-free asset price process if the set of investors can be chosen freely. However, empirical results on asset prices show a quite robust structure, suggesting that the general model can be simplified without losing empirical content. Properties of fund separation are very useful in this respect, since they introduce simple structures on asset allocation decisions that help to organize the data. 
In this paper, we have investigated the conditions for separating the consumption decision from the asset allocation decision in a $T$-period general equilibrium model. We call this property $T$-period fund separation. It is found that with logarithmic utilities, $T$-period fund separation holds for heterogeneous discount factors, while in the more general case of CRRA, homogeneous discount factors must be assumed. The empirical analysis shows that our data support a risk aversion smaller than in the logarithmic case. The conditions found are strong enough to represent the economy by a single representative investor whose decision problem not only generates a given path of asset prices, but who is also able to predict correctly the changes in asset prices resulting from changes in the dividend process.

Our asset pricing results are based on simplifying assumptions restricting the heterogeneity of agents. It would be interesting to see to what extent these results could be reproduced by introducing a high degree of heterogeneity of investors. For the static general equilibrium model, it is well known that going to the other extreme by allowing for any degree of heterogeneity would also lead to useful structures for market demand, and hence for equilibrium prices (e.g., Grandmont (1992), Quah (1997)). We hope that our paper helps to extend these results to the dynamic general equilibrium model of a financial market considered here.

\section{Appendix. Proofs}

General Considerations. In the following we derive the first-order condition (3) for the optimization problem (2). The first-order condition for an interior solution $\lambda^{i}$ to problem (2) is given by

$$
\frac{\partial U^{i}\left(c^{i}\left(\lambda^{i}, q\right)\right)}{\partial \lambda_{k}^{i}\left(\xi_{t}\right)}=\alpha^{i}\left(\xi_{t}\right)
$$

for all $k=0, \ldots, K$, all $\xi_{t} \in F_{t}$, and all $t=0, \ldots, T-1$, where $\alpha^{i}\left(\xi_{t}\right)$ is a Lagrange multiplier. Hence, for all $k=1, \ldots, K$, and all $\xi_{t} \in F_{t}$,

$$
\begin{aligned}
& \frac{\partial U^{i}\left(c^{i}\left(\lambda^{i}, q\right)\right)}{\partial \lambda_{0}^{i}\left(\xi_{t}\right)}=\frac{\partial U^{i}\left(c^{i}\left(\lambda^{i}, q\right)\right)}{\partial \lambda_{k}^{i}\left(\xi_{t}\right)} \\
& \frac{\partial U^{i}\left(c^{i}\left(\lambda^{i}, q\right)\right)}{\partial \lambda_{0}^{i}\left(\xi_{t}\right)}=w^{i}\left(\xi_{t}\right) \partial_{\xi_{t}} U^{i}=\beta_{i}^{t} \pi\left(\xi_{t}\right) u^{i \prime}\left(c^{i}\left(\xi_{t}\right)\right) w^{i}\left(\xi_{t}\right),{ }^{16}
\end{aligned}
$$

where

$$
\partial_{\xi_{t}} U^{i}:=\frac{\partial U^{i}\left(c^{i}\right)}{\partial c^{i}\left(\xi_{t}\right)}
$$

Moreover,

$$
\begin{aligned}
\frac{\partial U^{i}}{\partial \lambda_{k}^{i}\left(\xi_{t}\right)} & =\sum_{\tau=t+1}^{T} \sum_{\xi_{\tau} \subset \xi_{t}} \partial_{\xi_{\tau}} U^{i} \lambda_{0}^{i}\left(\xi_{\tau}\right) \frac{\partial w^{i}\left(\xi_{\tau}\right)}{\partial \lambda_{k}^{i}\left(\xi_{t}\right)} \\
& =\sum_{\tau=t+1}^{T} \sum_{\xi_{\tau} \subset \xi_{t}} \beta_{i}^{\tau} \pi\left(\xi_{\tau}\right) u^{i \prime}\left(c^{i}\left(\xi_{\tau}\right)\right) \lambda_{0}^{i}\left(\xi_{\tau}\right) \frac{\partial w^{i}\left(\xi_{\tau}\right)}{\partial \lambda_{k}^{i}\left(\xi_{t}\right)}
\end{aligned}
$$

\footnotetext{
${ }^{16}$ Here and in the following we write, in short, $c^{i}\left(\xi_{t}\right)$ instead of $c^{i}\left(\lambda^{i}, q\right)\left(\xi_{t}\right)$
} 
Let $\xi_{\tau} \subset \xi_{t}$ and let $\xi_{t+1}, \ldots, \xi_{\tau-1}$ be the unique predecessors of $\xi_{\tau}$ in periods $t+$ $1, \ldots, \tau-1$. Then

$$
\begin{aligned}
\frac{\partial w^{i}\left(\xi_{\tau}\right)}{\partial \lambda_{k}^{i}\left(\xi_{t}\right)} & =w_{0}^{i} \frac{D^{k}\left(\xi_{t+1}\right)+q^{k}\left(\xi_{t+1}\right)}{q^{k}\left(\xi_{t}\right)} \prod_{\substack{s=0 \\
s \neq t}}^{\tau-1}\left[\sum_{k=1}^{K} \frac{D^{k}\left(\xi_{s+1}\right)+q^{k}\left(\xi_{s+1}\right)}{q^{k}\left(\xi_{s}\right)} \lambda_{k}^{i}\left(\xi_{s}\right)\right] \\
& =w^{i}\left(\xi_{t}\right) \frac{D^{k}\left(\xi_{t+1}\right)+q^{k}\left(\xi_{t+1}\right)}{q^{k}\left(\xi_{t}\right)} \prod_{s=t+1}^{\tau-1}\left[\sum_{k=1}^{K} \frac{D^{k}\left(\xi_{s+1}\right)+q^{k}\left(\xi_{s+1}\right)}{q^{k}\left(\xi_{s}\right)} \lambda_{k}^{i}\left(\xi_{s}\right)\right] \\
& =\frac{w^{i}\left(\xi_{t}\right)}{w^{i}\left(\xi_{t+1}\right)} w^{i}\left(\xi_{\tau}\right) \frac{D^{k}\left(\xi_{t+1}\right)+q^{k}\left(\xi_{t+1}\right)}{q^{k}\left(\xi_{t}\right)} .
\end{aligned}
$$

Hence, the first-order condition becomes

$$
\begin{aligned}
q_{t}^{k} & =\sum_{\tau=t+1}^{T} \beta_{i}^{\tau-t} \mathrm{E}_{t}\left[\frac{u^{i \prime}\left(c_{\tau}^{i}\right)}{u^{i \prime}\left(c_{t}^{i}\right)} \frac{w_{\tau}^{i}}{w_{t+1}^{i}} \lambda_{\tau 0}^{i}\left(D_{t+1}^{k}+q_{t+1}^{k}\right)\right] \\
& =\sum_{\tau=t+1}^{T} \beta_{i}^{\tau-t} \mathrm{E}_{t}\left[\frac{u^{i \prime}\left(c_{\tau}^{i}\right)}{u^{i \prime}\left(c_{t}^{i}\right)} \frac{c_{\tau}^{i}}{c_{t+1}^{i}} \lambda_{t+1,0}^{i}\left(D_{t+1}^{k}+q_{t+1}^{k}\right)\right] \\
& =\sum_{\tau=t+1}^{T} \beta_{i}^{\tau-t} \mathrm{E}_{t}\left[\left(\frac{c_{t}^{i}}{c_{\tau}^{i}}\right)^{\eta} \frac{c_{\tau}^{i}}{c_{t+1}^{i}} \lambda_{t+1,0}^{i}\left(D_{t+1}^{k}+q_{t+1}^{k}\right)\right],
\end{aligned}
$$

for all $t=0, \ldots, T-1$ and all $k=1, \ldots, K$, where $\mathrm{E}_{t}[\cdot]$ denotes the expectation conditional on the sigma-algebra induced by the partition $F_{t}$. This proves the first-order condition (3).

Proof of Theorem 1. The first-order condition (3) for $\eta=1$ reads

$$
q_{t}^{k}=\sum_{\tau=t+1}^{T} \beta_{i}^{\tau-t} \mathrm{E}_{t}\left[\frac{c_{t}^{i}}{c_{t+1}^{i}} \lambda_{t+1,0}^{i}\left(D_{t+1}^{k}+q_{t+1}^{k}\right)\right] .
$$

If there exists an equilibrium with $T$-period fund separation, then, for all $l$ and all $t$ there exists $\bar{\lambda}_{t l}$ such that $\lambda_{t l}^{i}=\left(1-\lambda_{t 0}^{i}\right) \bar{\lambda}_{t l}$ for all $i$, which implies

$$
q_{t}^{l}=\sum_{j} \lambda_{t l}^{j} w_{t}^{j}=\bar{\lambda}_{t l} \sum_{j}\left(1-\lambda_{t 0}^{j}\right) w_{t}^{j}
$$

and hence

$$
\begin{aligned}
\frac{c_{t}^{i}}{c_{t+1}^{i}} \lambda_{t+1,0}^{i} & =\frac{\lambda_{t 0}^{i} w_{t}^{i}}{w_{t+1}^{i}} \\
& =\frac{\lambda_{t 0}^{i}}{\sum_{l} \frac{D_{t+1}^{l}+q_{t+1}^{l}}{q_{t}^{l}} \lambda_{t l}^{i}} \\
& =\frac{\lambda_{t 0}^{i}}{1-\lambda_{t 0}^{i}} \sum_{j}\left(1-\lambda_{t 0}^{j}\right) w_{t}^{j} \bar{D}_{t+1}+\bar{q}_{t+1}
\end{aligned}
$$

where

$$
\bar{q}_{t}:=\sum_{l=1}^{K} q_{t}^{l} \quad \text { for all } t=0, \ldots, T-1 .
$$


Substituting this into equation (A-1) gives

$$
\bar{\lambda}_{t k}=\sum_{\tau=t+1}^{T} \beta_{i}^{\tau-t} \frac{\lambda_{t 0}^{i}}{1-\lambda_{t 0}^{i}} \mathrm{E}_{t}\left[\frac{D_{t+1}^{k}+q_{t+1}^{k}}{\bar{D}_{t+1}+\bar{q}_{t+1}}\right] .
$$

Since $\sum_{k=1}^{K} \bar{\lambda}_{t k}=1$, it follows that

$$
\begin{aligned}
\lambda_{t 0}^{i} & =\frac{1}{1+\sum_{\tau=t+1}^{T} \beta_{i}^{\tau-t}}=\frac{1-\beta_{i}}{1-\beta_{i}^{T+1-t}} \quad \text { and } \\
\bar{\lambda}_{t k} & =\mathrm{E}_{t}\left[\frac{D_{t+1}^{k}+q_{t+1}^{k}}{\bar{D}_{t+1}+\bar{q}_{t+1}}\right],
\end{aligned}
$$

for all $i$, for all $k=1, \ldots, K$, and all $t=0, \ldots, T-1$. From

$$
\bar{q}_{t+1}=\sum_{j}\left(1-\lambda_{t+1,0}^{j}\right) w_{t+1}^{j},
$$

it follows that

$$
q_{t+1}^{k}=\bar{\lambda}_{t+1, k} \bar{q}_{t+1}
$$

and hence

$$
\bar{\lambda}_{t k}=\mathrm{E}_{t}\left[\frac{D_{t+1}^{k}+\bar{\lambda}_{t+1, k} \bar{q}_{t+1}}{\bar{D}_{t+1}+\bar{q}_{t+1}}\right] .
$$

Therefore, it remains to solve for $\bar{q}_{t}$, for all $t=0, \ldots, T-1$. For $t=0$, we have

$$
\begin{aligned}
\bar{q}_{0} & =\sum_{j}\left(1-\lambda_{00}^{j}\right) w_{0}^{j}=\sum_{j}\left(1-\lambda_{00}^{j}\right)\left(D_{0}+q_{0}\right) \delta^{j} \bar{\theta} \\
& =\left(\bar{D}_{0}+\bar{q}_{0}\right) \sum_{j}\left(1-\lambda_{00}^{j}\right) \delta^{j} .
\end{aligned}
$$

This implies

$$
\bar{q}_{0}=\bar{D}_{0} \frac{\sum_{j}\left(1-\lambda_{00}^{j}\right) \delta^{j}}{\sum_{j} \lambda_{00}^{j} \delta^{j}}
$$

Since

$$
\begin{aligned}
w_{t+1}^{j} & =\left(1-\lambda_{t 0}^{j}\right) w_{t}^{j} \sum_{k} \bar{\lambda}_{t k} \frac{D_{t+1}^{k}+q_{t+1}^{k}}{q_{t}^{k}} \\
& =\left(1-\lambda_{t 0}^{j}\right) w_{t}^{j} \frac{\bar{D}_{t+1}+\bar{q}_{t+1}}{\bar{q}_{t}} \\
& =\cdots \\
& =w_{0}^{j} \prod_{\tau=0}^{t}\left(\left(1-\lambda_{\tau 0}^{j}\right) \frac{\bar{D}_{\tau+1}+\bar{q}_{\tau+1}}{\bar{q}_{\tau}}\right),
\end{aligned}
$$


it follows that

$$
\begin{aligned}
\bar{q}_{t+1} & =\sum_{j}\left(1-\lambda_{t+1,0}^{j}\right) w_{t+1}^{j} \\
& =\prod_{\tau=0}^{t}\left(\frac{\bar{D}_{\tau+1}+\bar{q}_{\tau+1}}{\bar{q}_{\tau}}\right) \sum_{j}\left(w_{0}^{j} \prod_{\tau=0}^{t+1}\left(1-\lambda_{\tau, 0}^{j}\right)\right) \\
& =\left(\bar{D}_{0}+\bar{q}_{0}\right) \prod_{\tau=0}^{t}\left(\frac{\bar{D}_{\tau+1}+\bar{q}_{\tau+1}}{\bar{q}_{\tau}}\right) \sum_{j}\left(\delta^{j} \prod_{\tau=0}^{t+1}\left(1-\lambda_{\tau, 0}^{j}\right)\right) .
\end{aligned}
$$

From

$$
1-\lambda_{t 0}^{i}=\beta_{i} \frac{1-\beta_{i}^{T-t}}{1-\beta_{i}^{T+1-t}}
$$

we compute

$$
\prod_{\tau=0}^{t+1}\left(1-\lambda_{\tau, 0}^{i}\right)=\frac{\beta_{i}^{t+2}-\beta_{i}^{T+1}}{1-\beta_{i}^{T+1}}
$$

and hence

$$
\text { (A-4) } \quad \bar{q}_{t+1}=\left(\bar{D}_{0}+\bar{q}_{0}\right) \prod_{\tau=0}^{t}\left(\frac{\bar{D}_{\tau+1}+\bar{q}_{\tau+1}}{\bar{q}_{\tau}}\right) \sum_{j}\left(\frac{\beta_{j}^{t+2}-\beta_{j}^{T+1}}{1-\beta_{j}^{T+1}} \delta^{j}\right),
$$

for $t=0, \ldots, T-1$. From equation (A-4) we can solve for $\bar{q}_{t}$ for all $t$ and it is straightforward to verify that

$$
\bar{q}_{t}=\bar{D}_{t} \frac{\sum_{j}\left(\frac{\beta_{j}^{t+1}-\beta_{j}^{T+1}}{1-\beta_{j}^{T+1}} \delta^{j}\right)}{\sum_{j}\left(\frac{\beta_{j}^{t}-\beta_{j}^{t+1}}{1-\beta_{j}^{T+1}} \delta^{j}\right)}, \quad t=0, \ldots, T-1,
$$

solves equation (A-4) for all $t=0, \ldots, T-1$.

Given $\bar{q}_{t}$, it follows that

$$
\begin{aligned}
\bar{\lambda}_{t k} & =\mathrm{E}_{t}\left[\frac{D_{t+1}^{k}+\bar{\lambda}_{t+1, k} \bar{q}_{t+1}}{\bar{D}_{t+1}+\bar{q}_{t+1}}\right] \\
& =\frac{\sum_{j}\left(\frac{\beta_{j}^{t+1}-\beta_{j}^{t+2}}{1-\beta_{j}^{T+1}} \delta^{j}\right)}{\sum_{j}\left(\frac{\beta_{j}^{t+1}-\beta_{j}^{T+1}}{1-\beta_{j}^{T+1}} \delta^{j}\right)} \mathrm{E}_{t}\left[d_{t+1}^{k}\right]+\frac{\sum_{j}\left(\frac{\beta_{j}^{t+2}-\beta_{j}^{T+1}}{1-\beta_{j}^{T+1}} \delta^{j}\right)}{\sum_{j}\left(\frac{\beta_{j}^{t+1}-\beta_{j}^{T+1}}{1-\beta_{j}^{T+1}} \delta^{j}\right)} \mathrm{E}_{t}\left[\bar{\lambda}_{t+1, k}\right],
\end{aligned}
$$

for all $k=1, \ldots, K$, and all $t=0, \ldots, T-1$. Solving for $\bar{\lambda}_{t k}$ recursively, we obtain

$$
\begin{aligned}
\bar{\lambda}_{t k} & =\frac{1}{\sum_{j}\left(\frac{\beta_{j}^{t+1}-\beta_{j}^{T+1}}{1-\beta_{j}^{T+1}} \delta^{j}\right)} \sum_{\tau=t+1}^{T}\left(\sum_{j} \frac{\beta_{j}^{\tau}-\beta_{j}^{\tau+1}}{1-\beta_{j}^{T+1}} \delta^{j}\right) \mathrm{E}_{t}\left[d_{\tau}^{k}\right], \quad \text { and } \\
q_{t}^{k} & =\bar{\lambda}_{t k} \bar{q}_{t}=\bar{D}_{t} \frac{1}{\sum_{j}\left(\frac{\beta_{j}^{t}-\beta_{j}^{t+1}}{1-\beta_{j}^{T+1}} \delta^{j}\right)} \sum_{\tau=t+1}^{T}\left(\sum_{j} \frac{\beta_{j}^{\tau}-\beta_{j}^{\tau+1}}{1-\beta_{j}^{T+1}} \delta^{j}\right) \mathrm{E}_{t}\left[d_{\tau}^{k}\right]
\end{aligned}
$$

for all $k=1, \ldots, K$, and all $t=0, \ldots, T-1$. This proves the theorem. 
Proof of Theorem 3. If $(\lambda, q)$ is an equilibrium with $T$-period fund separation then, for all $l$ and all $t$, there exists $\bar{\lambda}_{t l}$ such that $\lambda_{t l}^{i}=\left(1-\lambda_{t 0}^{i}\right) \bar{\lambda}_{t l}$ for all $i$. As before, this implies that

$$
q_{t}^{l}=\sum_{j} \lambda_{t l}^{j} w_{t}^{j}=\bar{\lambda}_{t l} \sum_{j}\left(1-\lambda_{t 0}^{j}\right) w_{t}^{j},
$$

for all $l$ and all $t$. For all $\tau>t$, we have

$$
w_{\tau}^{i}=w_{t}^{i} \prod_{s=t}^{\tau-1}\left[\frac{\left(\bar{D}_{s+1}+\bar{q}_{s+1}\right)\left(1-\lambda_{s 0}^{i}\right)}{\sum_{j}\left(1-\lambda_{s 0}^{j}\right) w_{s}^{j}}\right] .
$$

Substituting this into the first-order condition (3) for the case where $\beta_{i}=\beta$ for all $i$ and $\eta \neq 1$, we obtain

$$
\begin{gathered}
\bar{\lambda}_{t k}\left[\sum_{j}\left(1-\lambda_{t 0}^{j}\right) w_{t}^{j}\right]^{1-\eta}=\sum_{\tau=t+1}^{T} \beta^{\tau-t} \mathrm{E}_{t}\left[\left(\frac{\lambda_{t 0}^{i}}{1-\lambda_{t 0}^{i}}\right)^{\eta}\left(\lambda_{\tau 0}^{i}\right)^{1-\eta}\right. \\
\left.\frac{D_{t+1}^{k}+q_{t+1}^{k}}{\left(\bar{D}_{t+1}+\bar{q}_{t+1}\right)^{\eta}} \prod_{s=t+1}^{\tau-1}\left[\frac{\left(\bar{D}_{s+1}+\bar{q}_{s+1}\right)\left(1-\lambda_{s 0}^{i}\right)}{\sum_{j}\left(1-\lambda_{s 0}^{j}\right) w_{s}^{j}}\right]^{1-\eta}\right]
\end{gathered}
$$

Since $\sum_{k} \bar{\lambda}_{t k}=1$, this implies

$$
\begin{gathered}
{\left[\sum_{j}\left(1-\lambda_{t 0}^{j}\right) w_{t}^{j}\right]^{1-\eta}=\sum_{\tau=t+1}^{T} \beta^{\tau-t} \mathrm{E}_{t}\left[\left(\frac{\lambda_{t 0}^{i}}{1-\lambda_{t 0}^{i}}\right)^{\eta}\left(\lambda_{\tau 0}^{i}\right)^{1-\eta}\right.} \\
\left.\left(\bar{D}_{t+1}+\bar{q}_{t+1}\right)^{1-\eta} \prod_{s=t+1}^{\tau-1}\left[\frac{\left(\bar{D}_{s+1}+\bar{q}_{s+1}\right)\left(1-\lambda_{s 0}^{i}\right)}{\sum_{j}\left(1-\lambda_{s 0}^{j}\right) w_{s}^{j}}\right]^{1-\eta}\right] .
\end{gathered}
$$

Let $t=T-1$. Then, for all $i$ and given $\left(\lambda_{T-1,0}^{j}\right)_{j \neq i}$, there exists a unique solution $\lambda_{T-1,0}^{i}$ to equation (A-6). Since $\lambda_{T 0}^{i}=1$ for all $i$, it is evident that $\lambda_{T-1,0}^{i}=\lambda_{T-1,0}$ for all $i$ if $\left(\lambda_{T-1,0}^{i}\right)_{i}$ solves equation (A-6) simultaneously for all $i$. By induction, it then follows that $\lambda_{t 0}^{i}=\lambda_{t 0}$ for all $i$ and all $0 \leq t \leq T-1$.

This implies that

$$
q_{t}^{l}=\left(1-\lambda_{t 0}\right) \bar{\lambda}_{t l} \sum_{j} w_{t}^{j}=\left(1-\lambda_{t 0}\right) \bar{\lambda}_{t l}\left(\bar{D}_{t}+\bar{q}_{t}\right), \quad t=0, \ldots, T-1 .
$$

Substituting this into equation (A-5), we get

$$
\bar{\lambda}_{t k}=\frac{\left(\lambda_{t 0}\right)^{\eta}}{1-\lambda_{t 0}} \sum_{\tau=t+1}^{T} \beta^{\tau-t} \mathrm{E}_{t}\left[\left(\lambda_{\tau, 0}\right)^{1-\eta}\left(\frac{\bar{D}_{\tau}+\bar{q}_{\tau}}{\bar{D}_{t}+\bar{q}_{t}}\right)^{1-\eta} \frac{D_{t+1}^{k}+q_{t+1}^{k}}{\bar{D}_{t+1}+\bar{q}_{t+1}}\right]
$$

for $t=0, \ldots, T-1$.

We now solve for the equilibrium price $q$. We have already seen that

$$
q_{t}^{k}=\bar{\lambda}_{t k}\left(1-\lambda_{t 0}\right)\left(\bar{D}_{t}+\bar{q}_{t}\right),
$$

for $t=0, \ldots, T-1$. Summing over all $k$, we get

$$
\begin{aligned}
\bar{q}_{t} & =\left(1-\lambda_{t 0}\right)\left(\bar{D}_{t}+\bar{q}_{t}\right) \\
\Longleftrightarrow \quad \bar{q}_{t} & =\frac{1-\lambda_{t 0}}{\lambda_{t 0}} \bar{D}_{t}, \quad t=0, \ldots, T-1 .
\end{aligned}
$$


Substituting this into equation (A-7) gives

$$
\bar{\lambda}_{t k}=\frac{\lambda_{t 0}}{1-\lambda_{t 0}} \sum_{\tau=t+1}^{T} \beta^{\tau-t} \mathrm{E}_{t}\left[\left(\frac{\bar{D}_{\tau}}{\bar{D}_{t}}\right)^{1-\eta} \frac{D_{t+1}^{k}+q_{t+1}^{k}}{\bar{D}_{t+1}+\bar{q}_{t+1}}\right], \quad \text { for } t=0, \ldots, T-1 .
$$

Summing over all $k$ and solving for $\lambda_{t 0}$, we obtain that

$$
\lambda_{t 0}=\frac{\left(\bar{D}_{t}\right)^{1-\eta}}{\left(\bar{D}_{t}\right)^{1-\eta}+\sum_{\tau=t+1}^{T} \beta^{\tau-t} \mathrm{E}_{t}\left[\left(\bar{D}_{\tau}\right)^{1-\eta}\right]}, \quad t=0, \ldots, T-1 .
$$

Hence,

$$
\begin{aligned}
\bar{\lambda}_{t k}= & \frac{1}{\sum_{\tau=t+1}^{T} \beta^{\tau-t} \mathrm{E}_{t}\left[\left(\bar{D}_{\tau}\right)^{1-\eta}\right]} \sum_{\tau=t+1}^{T} \beta^{\tau-t} \mathrm{E}_{t}\left[\left(\bar{D}_{\tau}\right)^{1-\eta} \frac{D_{t+1}^{k}+q_{t+1}^{k}}{\bar{D}_{t+1}+\bar{q}_{t+1}}\right] \\
= & \frac{1}{\sum_{\tau=t+1}^{T} \beta^{\tau-t} \mathrm{E}_{t}\left[\left(\bar{D}_{\tau}\right)^{1-\eta}\right]} \sum_{\tau=t+1}^{T} \beta^{\tau-t} \mathrm{E}_{t}\left[( \overline { D } _ { \tau } ) ^ { 1 - \eta } \left(\lambda_{t+1,0} d_{t+1}^{k}\right.\right. \\
& \left.\left.\quad+\left(1-\lambda_{t+1,0}\right) \bar{\lambda}_{t+1, k}\right)\right] .
\end{aligned}
$$

Solving backwards for $\bar{\lambda}_{t k}$ gives

$$
\bar{\lambda}_{t k}=\frac{\sum_{\tau=t+1}^{T} \beta^{\tau-t} \mathrm{E}_{t}\left[\frac{D_{\tau}^{k}}{\left(\bar{D}_{\tau}\right)^{\eta}}\right]}{\sum_{\tau=t+1}^{T} \beta^{\tau-t} \mathrm{E}_{t}\left[\left(\bar{D}_{\tau}\right)^{1-\eta}\right]}
$$

for all $t=0, \ldots, T-1, k=1, \ldots, K$. This implies that

$$
\begin{aligned}
q_{t}^{k} & =\bar{\lambda}_{t k} \bar{q}_{t} \\
& =\bar{\lambda}_{t k}\left(\bar{D}_{t}\right)^{\eta} \sum_{\tau=t+1}^{T} \beta^{\tau-t} \mathrm{E}_{t}\left[\left(\bar{D}_{\tau}\right)^{1-\eta}\right] \\
& =\left(\bar{D}_{t}\right)^{\eta} \sum_{\tau=t+1}^{T} \beta^{\tau-t} \mathrm{E}_{t}\left[\frac{D_{\tau}^{k}}{\left(\bar{D}_{\tau}\right)^{\eta}}\right]
\end{aligned}
$$

for $t=0, \ldots, T-1$. The uniqueness of the equilibrium price vector follows from Theorem 2 .

Proof of Theorem 4. The proof is a simple adaptation of the corresponding proof for the case $T=1$ (see, e.g., Magill and Quinzii (1996), Prop. 16.13). Let $U^{i}(c)=\sum_{t=0}^{T} \beta_{i}^{t} \mathrm{E}\left[u^{i}\left(c_{t}\right)\right]$, where

$$
-\frac{u^{i \prime}(x)}{u^{i \prime}(x)}=a_{i}+b x
$$

for some constants $a_{i} \in \mathbb{R}_{+}$and $b \in \mathbb{R}$ and all $i=1, \ldots, I$. This implies

$$
u^{i}(x)=\left\{\begin{array}{ll}
\frac{\left(a_{i}+b x\right)^{1-1 / b}}{1 / b(1-1 / b)}, & \text { if } b \neq 0 \text { and } b \neq 1 \\
-a_{i} e^{-x / a_{i}} & , \text { if } b=0 \\
\ln \left(a_{i}+x\right) & , \text { if } b=1
\end{array} .\right.
$$


Let $\left(c^{i}\right)_{i}$ be a Pareto-efficient allocation. Then, there exists $\left(\mu^{i}\right)_{i}$ with $\mu^{i} \geq 0$ for all $i$ such that $\left(c^{i}\right)_{i}$ solves

$$
\begin{array}{ll}
\max & \sum_{i} \mu^{i} U^{i}\left(c^{i}\right) \\
\text { s.t. } & \sum_{i} c_{t}^{i}=\bar{D}_{t}, \quad \text { for all } t=0, \ldots, T .
\end{array}
$$

Observe that $\mu^{i}=0$ implies that $c^{i}=0$, in which case we define $\alpha_{t}^{i}:=\gamma_{t}^{i}:=0$ for all $t$. Hence, if $\mu^{i}=0$, we can delete investor $i$ from the optimization problem (A-8) and consider the remaining investors only. Therefore, in the following we will assume that $\mu^{i}>0$ for all $i$. By strict concavity of $U^{i}$, the first-order condition for problem (A-8) is necessary and sufficient. It is given by

$$
\mu^{i} \frac{\partial U^{i}\left(c^{i}\right)}{\partial c^{i}\left(\xi_{t}\right)}=\mu^{1} \frac{\partial U^{1}\left(c^{1}\right)}{\partial c^{1}\left(\xi_{t}\right)}, \quad \text { for all } i \neq 1, \text { for all } \xi_{t}, \text { and for all } t=0, \ldots, T \text {. }
$$

Case 1. Let $b \neq 0$. Then the first-order condition reads

$$
\mu^{i} \beta_{i}^{t} \pi\left(\xi_{t}\right)\left(a_{i}+b c^{i}\left(\xi_{t}\right)\right)^{-1 / b} b=\mu^{1} \beta_{1}^{t} \pi\left(\xi_{t}\right)\left(a_{1}+b c^{1}\left(\xi_{t}\right)\right)^{-1 / b} b
$$

which is equivalent to

$$
a_{i}+b c^{i}\left(\xi_{t}\right)=\left(\frac{\mu^{i} \beta_{i}^{t}}{\mu^{1} \beta_{1}^{t}}\right)^{b}\left(a_{1}+b c^{1}\left(\xi_{t}\right)\right) .
$$

If we define $K_{t}^{i}:=\left(\left(\mu^{i} \beta_{i}^{t}\right) /\left(\mu^{1} \beta_{1}^{t}\right)\right)^{b}$, and $K_{t}:=\sum_{i} K_{t}^{i}$, we obtain

$$
a_{1}+b c^{1}\left(\xi_{t}\right)=\frac{\sum_{i} a_{i}+b \bar{D}\left(\xi_{t}\right)}{K_{t}},
$$

where we have used the fact that $\sum_{i} c^{i}\left(\xi_{t}\right)=\bar{D}\left(\xi_{t}\right)$. From this we compute

$$
c^{i}\left(\xi_{t}\right)=\frac{K_{t}^{i}}{K_{t}} \frac{\sum_{j} a_{j}}{b}-\frac{a_{i}}{b}+\frac{K_{t}^{i}}{K_{t}} \bar{D}\left(\xi_{t}\right) .
$$

Hence, if we define

$$
\alpha_{t}^{i}:=\frac{K_{t}^{i}}{K_{t}} \frac{\sum_{j} a_{j}}{b}-\frac{a_{i}}{b} \quad \text { and } \quad \gamma_{t}^{i} \quad:=\frac{K_{t}^{i}}{K_{t}},
$$

then $\alpha_{t}^{i}$ and $\gamma_{t}^{i}$ are independent of $\xi_{t}$ and $\sum_{i} \alpha_{t}^{i}=0$ and $\sum_{i} \gamma_{t}^{i}=1$. We have shown that

$$
c_{t}^{i}=\alpha_{t}^{i}+\gamma_{t}^{i} \bar{D}_{t}, \quad \text { for all } t=0, \ldots, T .
$$

By definition, if $a_{i}=0$ for all $i$ (CRRA utility), then $\alpha_{t}^{i}=0$ for all $i$ and for all $t$, and hence there is linear sharing in any Pareto-efficient allocation. If in addition $\beta_{i}=\beta$ for all $i$, then $K_{t}^{i}=\left(\mu^{i} / \mu^{1}\right)^{b}$ is independent of $t$, which implies that $\gamma_{t}^{i}$ is independent of $t$.

Case 2. Let $b=0$. Then the first-order condition reads

$$
\mu^{i} \beta_{i}^{t} \pi\left(\xi_{t}\right) e^{-c^{i}\left(\xi_{t}\right) / a_{i}}=\mu^{1} \beta_{1}^{t} \pi\left(\xi_{t}\right) e^{-c^{1}\left(\xi_{t}\right) / a_{1}},
$$


which is equivalent to

$$
\frac{c^{i}\left(\xi_{t}\right)}{a_{i}}=\frac{c^{1}\left(\xi_{t}\right)}{a_{1}}+\ln \left(\frac{\mu^{i} \beta_{i}^{t}}{\mu^{1} \beta_{1}^{t}}\right) .
$$

Define $K_{t}^{i}:=\ln \left(\left(\mu^{i} \beta_{i}^{t}\right) /\left(\mu^{1} \beta_{1}^{t}\right)\right)$. Then

$$
c^{i}\left(\xi_{t}\right)=\frac{a_{i}}{a_{1}} c^{1}\left(\xi_{t}\right)+a_{i} K_{t}^{i}
$$

From $\sum_{i} c^{i}\left(\xi_{t}\right)=\bar{D}\left(\xi_{t}\right)$, it follows that

$$
c^{1}\left(\xi_{t}\right)=\frac{a_{1}}{\sum_{j} a_{j}} \bar{D}\left(\xi_{t}\right)-\frac{a_{1}}{\sum_{j} a_{j}} \sum_{j} a_{j} K_{t}^{j},
$$

which implies

$$
c^{i}\left(\xi_{t}\right)=\alpha_{t}^{i}+\gamma_{t}^{i} \bar{D}\left(\xi_{t}\right),
$$

where $\alpha_{t}^{i}=a_{i} K_{t}^{i}-\left(a_{i} /\left(\sum_{j} a_{j}\right)\right) \sum_{j} a_{j} K_{t}^{j}$ and $\gamma_{t}^{i}=a_{i} /\left(\sum_{j} a_{j}\right)$. Observe that again $\alpha_{t}^{i}$ and $\gamma_{t}^{i}$ are independent of $\xi_{t}$ and that $\sum_{i} \alpha_{t}^{i}=0$ and $\sum_{i} \gamma_{t}^{i}=1$.

Proof of Theorem 5. Let $c^{* i}$ be investor $i$ 's consumption in the equilibrium with $T$-period fund separation, $\left(\lambda^{*}, q^{*}\right)$, as characterized in Theorem 1 , respectively Theorem 3 . Then, for all $t=0, \ldots, T-1$ and all $i$,

$$
\begin{aligned}
w_{t+1}^{i} & =\frac{w_{0}^{i} \prod_{\tau=0}^{t}\left(1-\lambda_{\tau 0}^{* i}\right)}{\sum_{j}\left(w_{0}^{j} \prod_{\tau=0}^{t}\left(1-\lambda_{\tau 0}^{* j}\right)\right)}\left(\bar{D}_{t+1}+\bar{q}_{t+1}\right) \\
& =w_{0}^{i} Z_{t+1} \prod_{\tau=0}^{t}\left(1-\lambda_{\tau 0}^{* i}\right),
\end{aligned}
$$

where $Z_{t+1}$ is independent of $i$. This implies

$$
\frac{c_{0}^{* i}}{c_{t+1}^{* i}}=\frac{\lambda_{00}^{* i} w_{0}^{i}}{\lambda_{t+1,0}^{* i} w_{t+1}^{i}}=\frac{\lambda_{00}^{* i}}{Z_{t+1} \lambda_{t+1,0}^{* i} \prod_{\tau=0}^{t}\left(1-\lambda_{\tau 0}^{* i}\right)} .
$$

By Theorem 1 , if $\eta=1$, then $\lambda_{t 0}^{* i}=\left(1-\beta_{i}\right) /\left(1-\beta_{i}^{T+1-t}\right)$ for all $t$. Hence,

$$
\frac{\lambda_{00}^{* i}}{\lambda_{t+1,0}^{* i} \prod_{\tau=0}^{t}\left(1-\lambda_{\tau 0}^{* i}\right)}=\frac{1}{\beta_{i}^{t+1}}
$$

which implies

$$
\beta_{i}^{t+1} \frac{c_{0}^{* i}}{c_{t+1}^{* i}}=\frac{1}{Z_{t+1}}
$$

and

$$
\frac{\partial_{\xi_{t+1}} U^{i}\left(c^{* i}\right)}{\partial_{\xi_{0}} U^{i}\left(c^{* i}\right)}=\beta_{i}^{t+1} \pi\left(\xi_{t+1}\right) \frac{c_{0}^{* i}}{c^{* i}\left(\xi_{t+1}\right)}=\frac{\pi\left(\xi_{t+1}\right)}{Z\left(\xi_{t+1}\right)},
$$

which is independent of $i$. 
Let $\eta \neq 1$ and $\beta_{i}=\beta$ for all $i$. Then, by Theorem $3, \lambda_{t 0}^{* i}=\lambda_{t 0}^{*}$ is independent of $i$ for all $t$. This implies $w_{t+1}^{i}=\left(w_{0}^{i} /\left(\sum_{j} w_{0}^{j}\right)\right)\left(\bar{D}_{t+1}+\bar{q}_{t+1}\right)$. Hence,

$$
\frac{c_{0}^{* i}}{c_{t+1}^{* i}}=\frac{\lambda_{00}^{*}\left(\bar{D}_{0}+\bar{q}_{0}\right)}{\lambda_{t+1,0}^{*}\left(\bar{D}_{t+1}+\bar{q}_{t+1}\right)}
$$

is independent of $i$. Therefore,

$$
\begin{aligned}
\frac{\partial_{\xi_{t+1}} U^{i}\left(c^{* i}\right)}{\partial_{\xi_{0}} U^{i}\left(c^{* i}\right)} & =\beta^{t+1} \pi\left(\xi_{t+1}\right)\left(\frac{c_{0}^{* i}}{c^{* i}\left(\xi_{t+1}\right)}\right)^{\eta} \\
& =\beta^{t+1} \pi\left(\xi_{t+1}\right)\left(\frac{\lambda_{00}^{*}\left(\bar{D}_{0}+\bar{q}_{0}\right)}{\lambda_{t+1,0}^{*}\left(\bar{D}_{t+1}+\bar{q}_{t+1}\right)}\right)^{\eta},
\end{aligned}
$$

which is independent of $i$. Thus, in both cases the agent's utility gradients are collinear in equilibrium, $\nabla U^{i}\left(c^{* i}\right) \| \nabla U^{j}\left(c^{* j}\right)$ for all $i \neq j$, which implies the Pareto efficiency of the equilibrium allocation $\left(c^{* i}\right)_{i}$.

Proof of Theorem 6. Let $\left(\lambda^{*}, q^{*}\right)$ be an equilibrium with $T$-period fund separation for the economy. Then, by Theorem 5 , the corresponding consumption allocation $\left(c^{* i}\right)$ is Pareto efficient. Hence, the agents' utility gradients $\nabla U^{i}\left(c^{* i}\right)$ are collinear, $\nabla U^{i}\left(c^{* i}\right) \| \nabla U^{j}\left(c^{* j}\right)$ for all $i \neq j$. For all $i=1, \ldots, I$, define

$$
\gamma_{i}:=\frac{1}{\partial_{\xi_{0}} U^{i}\left(c^{* i}\right)}=\left(c_{0}^{* i}\right)^{\eta} .
$$

If $\eta=1$, define $\hat{U}: \mathbb{R}_{++}^{d} \rightarrow \mathbb{R}$ by

$$
\hat{U}(c):=\sup \left\{\sum_{i} \gamma_{i} U^{i}\left(c^{i}\right) \mid \sum_{i} c^{i}=c, c^{i} \in \mathbb{R}_{++}^{d} \text { for all } i\right\}, \quad c \in \mathbb{R}_{++}^{d} .
$$

If $\eta \neq 1$, define $\hat{U}: \mathbb{R}_{+}^{d} \rightarrow \mathbb{R}$ accordingly. Then $\hat{U}(\bar{c})=\sum_{i} \gamma_{i} U^{i}\left(\bar{c}^{i}\right)$ if and only if

$$
\gamma_{i} \nabla U^{i}\left(\bar{c}^{i}\right)=\gamma_{j} \nabla U^{j}\left(\bar{c}^{j}\right), \quad \text { for all } i \neq j .
$$

Moreover,

$$
\nabla \hat{U}(\bar{c})=\gamma_{i} \nabla U^{i}\left(\bar{c}^{i}\right), \text { for all } i
$$

Let $\bar{e} \in \mathbb{R}_{++}^{d}$ be given by $\bar{e}_{t}=\bar{D}_{t}$ for all $t$. Then, $\bar{e}=\sum_{i} c^{* i}$ and by definition of $\hat{U}$ it follows that

$$
\hat{U}(\bar{e})=\sum_{i} \gamma_{i} U^{i}\left(c^{* i}\right)
$$

Hence, by equation (A-9), $q^{*}$ is an equilibrium price vector in the representative agent economy, where the agent has utility function $\hat{U}$ and endowment $\bar{e}$.

Since all $U^{i}$ are in expected utility form, $\hat{U}$ has expected utility form as well. Consider first the case where all investors in the heterogeneous agent economy have unit constant relative risk aversion. Then, it is straightforward to show that $\hat{U}$ is given by

$$
\hat{U}(c)=\mathrm{E}\left[\sum_{t=0}^{T}\left(A_{t}+B_{t} \ln \left(c_{t}\right)\right)\right], \quad \text { for all } \quad c \in \mathbb{R}_{++}^{d}
$$


where

$$
A_{t}=\sum_{i} \gamma_{i} \beta_{i}^{t} \ln \left(\alpha_{t}^{i}\right) \quad \text { and } \quad B_{t}=\sum_{i} \gamma_{i} \beta_{i}^{t}
$$

and $\alpha_{t}^{i}=\gamma_{i} \beta_{i}^{t} / \sum_{j} \gamma_{j} \beta_{j}^{t}$ for all $i$ and $t=0, \ldots, T$. Hence, a monotone transformation of $\hat{U}$ has expected logarithmic utility form and therefore, the representative agent has unit CRRA.

Similarly, if all investors in the heterogeneous agent economy have CRRA $\eta \neq 1$ and the same discount factor $\beta$, then $\hat{U}$ is given by

$$
\hat{U}(c)=\mathrm{E}\left[\sum_{t=0}^{T} G_{t} \frac{1}{1-\eta}\left(c_{t}\right)^{1-\eta}\right], \quad \text { for all } \quad c \in \mathbb{R}_{+}^{d},
$$

where $G_{t}=\beta^{t}\left(\sum_{i}\left(\gamma_{i}\right)^{\frac{1}{\eta}}\right)^{\eta}$ for all $t=0, \ldots, T$. Hence, the representative agent has CRRA equal to $\eta$.

Finally, observe that $\gamma_{i}$ only depends on $\left(\beta_{j}\right)_{j},\left(\delta^{j}\right)_{j}$, and $\bar{D}_{0}$ for all $i$ :

$$
c_{0}^{* i}=\lambda_{00}^{* i} w_{0}^{i}=\lambda_{00}^{* i} \delta^{i}\left(\bar{D}_{0}+\bar{q}_{0}\right)=\frac{\lambda_{00}^{* i} \delta^{i}}{\sum_{j} \lambda_{00}^{* j} \delta^{j}} \bar{D}_{0} .
$$

If $\eta \neq 1$, then

$$
\gamma_{i}=\left(c_{0}^{* i}\right)^{\eta}=\left(\delta^{i} \bar{D}_{0}\right)^{\eta} .
$$

If $\eta=1$, then

$$
\gamma_{i}=c_{0}^{* i}=\frac{1-\beta_{i}}{1-\beta_{i}^{T+1}} \delta^{i}\left(\sum_{j} \frac{1-\beta_{j}}{1-\beta_{j}^{T+1}} \delta^{j}\right)^{-1} \bar{D}_{0} .
$$

Hence, $\hat{U}$ is independent of the future dividend process $\left(D_{t}\right)_{t=1, \ldots, T}$.

\section{References}

Algoet, P. H., and T. M. Cover. "Asymptotic Optimality and Asymptotic Equipartition Properties of Log-Optimum Investment." Annals of Probability, 16 (1988), 876-898.

Antonelli, G. B. "Sulla Teoria Matematica della Economia Politica." Pisa, Italy: Nella Tipografia del Folchetto (1886). English translation by J. S. Chipman and A. P. Kirman in Preferences, Utility, and Demand, J. S. Chipman, L. Hurwicz, M. K. Richter, and H. F. Sonnenschein, eds. New York, NY: Harcourt Brace Jovanovich, Inc. (1971).

Barberis, N., and M. Huang. "Mental Accounting, Loss Aversion, and Individual Stock Returns." Journal of Finance, 56 (2001), 1247-1292.

Black, F., and M. Scholes. "The Effects of Dividend Yield and Dividend Policy on Common Stock Prices and Returns." Journal of Financial Economics, 1 (1974), 1-22.

Breiman, L. "Optimal Gambling Systems for Favorable Games." Fourth Berkeley Symposium on Mathematical Statistics and Probability, 1 (1961), 65-78.

Browne, S. "The Return on Investment from Proportional Portfolio Strategies." Advances in Applied Probability, 30 (1998), 216-238.

Campbell, J. Y., and J. H. Cochrane. "By Force of Habit: A Consumption-Based Explanation of Aggregate Stock Market Behavior." Journal of Political Economy, 107 (1999), 205-251.

Campbell, J. Y., and R. J. Shiller. "The Dividend-Price Ratio and Expectations of Future Dividends and Discount Factors." Review of Financial Studies, 1 (1988), 195-228.

Cass, D., and J. E. Stiglitz. "The Structure of Investor Preference and Asset Returns and Separability in Portfolio Allocation: A Contribution to the Pure Theory of Mutual Funds." Journal of Economic Theory, 2 (1970), 122-160. 
Cochrane, J. H. “A Cross-Sectional Test of an Investment-Based Asset Pricing Model.” Journal of Political Economy, 104 (1996), 572-621.

Constantinides, G. M. "Intertemporal Asset Pricing with Heterogeneous Consumers and without Demand Aggregation.” Journal of Business, 55 (1982), 253-267.

Dempster, M. A. H. Risk Management: Value at Risk and Beyond. Cambridge, UK: Cambridge University Press (2002).

Dempster, M. A. H.; M. Germano; E. A. Medova; and M. Villaverde. "Global Asset Liability Management." British Actuarial Journal, 9 (2003), 137-195.

Den Haan, W. J., and A. Marcet. "Solving the Stochastic Growth Model by Parameterizing Expectations." Journal of Business \& Economic Statistics, 8 (1990), 31-34.

Detemple, J., and P. Gottardi. "Aggregation, Efficiency and Mutual Fund Separation in Incomplete Markets.” Economic Theory, 11 (1998), 443-455.

Dickey, D. A., and W. A. Fuller. "Distribution of the Estimators for Autoregressive Time Series with a Unit Root." Journal of the American Statistical Association, 74 (1979), 427-431.

Dimson, E., and P. Marsh. "The Demise of Size." In Security Market Imperfections in World Wide Equity Markets, chap. 6, D. B. Keim and W. T. Ziemba, eds. Cambridge, UK: Cambridge University Press (2000).

Evstigneev, I. V.; T. Hens; and K. R. Schenk-Hoppé. "Evolutionary Stable Stock Markets.” Economic Theory, 27 (2006), 449-468.

Evstigneev, I. V.; T. Hens; and K. R. Schenk-Hoppé. "Globally Evolutionarily Stable Portfolio Rules.” Journal of Economic Theory, 140 (2008), 197-228.

Fama, E. F., and K. R. French. "Dividend Yields and Expected Stock Returns." Journal of Financial Economics, 22 (1988), 3-25.

Goetzmann, W. N., and P. Jorion. "A Longer Look at Dividend Yields.” Journal of Business, 68 (1995), 483-508.

Gollier, C. The Economics of Risk and Time. Cambridge, MA: MIT Press (2001).

Grandmont, J. M. "Transformations of the Commodity Space, Behavioral Heterogeneity, and the Aggregation Problem.” Journal of Economic Theory, 57 (1992), 1-35.

Hagiwara, M., and M. A. Herce. "Risk Aversion and Stock Price Sensitivity to Dividends." American Economic Review, 87 (1997), 738-745.

Hakansson, N. H. "Optimal Investment and Consumption Strategies under Risk for a Class of Utility Functions.” Econometrica, 38 (1970), 587-607.

Hakansson, N. H., and W. T. Ziemba. "Capital Growth Theory.” In Handbooks in Operations Research and Management Science, Vol. 9 (Finance), chap. 3, R. A. Jarrow, V. Maksimovic, and W. T. Ziemba, eds. Amsterdam: Elsevier BV (1995).

Hens, T.; S. Reimann; and B. Vogt. "Nash Competitive Equilibria and Two-Period Fund Separation." Journal of Mathematical Economics, 40 (2004), 321-346.

Huang, C.-F., and R. H. Litzenberger. Foundations for Financial Economics. New York, NY: NorthHolland (1988).

Ingersoll, J. E., Jr. Theory of Financial Decision Making. Savage, MD: Rowman \& Littlefield Publishers (1987).

Jagannathan, R., and Z. Wang. "The Conditional CAPM and the Cross-Section of Expected Returns." Journal of Finance, 51 (1996), 3-53.

Jarque, C. M., and A. K. Bera. "A Test for Normality of Observations and Regression Residuals." International Statistical Review, 55 (1987), 163-172.

Judd, K. L.; F. Kubler; and K. Schmedders. "Bond Portfolios and Two-Fund Separation in the Lucas Asset-Pricing Model." Discussion Paper 1427, Northwestern University, Center for Mathematical Studies in Economics and Management Science (2006).

Keim, D. B. "Dividend Yields and Stock Returns: Implications of Abnormal January Returns." Journal of Financial Economics, 14 (1985), 473-489.

Kelly, J. L. “A New Interpretation of Information Rate.” Bell System Technical Journal, 35 (1956), 917-926.

Kocherlakota, N. R. “The Equity Premium: It's Still a Puzzle.” Journal of Economic Literature, 34 (1996), 42-71.

Kraus, A., and R. H. Litzenberger. "Market Equilibrium in a Multiperiod State Preference Model with Logarithmic Utility.” Journal of Finance, 30 (1975), 1213-1227.

Kydland, F. E., and E. C. Prescott. "Time to Build and Aggregate Fluctuations." Econometrica, 50 (1982), 1345-1370.

Lettau, M.; W. Semmler; and P. Woehrmann. "Nonparametric Estimation of Time-Varying Characteristics of Intertemporal Asset Pricing Models.” Working Paper, New School University (2007).

Litzenberger, R. H., and K. Ramaswamy. "The Effect of Personal Taxes and Dividends on Capital Asset Prices: Theory and Empirical Evidence." Journal of Financial Economics, 7 (1979), $163-195$. 
Litzenberger, R. H., and K. Ramaswamy. "Dividends, Short Selling Restrictions, Tax-Induced Investor Clienteles and Market Equilibrium." Journal of Finance, 35 (1980), 469-482.

Lucas, R. E. “Asset Prices in an Exchange Economy.” Econometrica, 46 (1978), 1429-1445.

Magill, M., and M. Quinzii. Theory of Incomplete Markets. Cambridge, MA: MIT Press (1996).

Mehra, R., and E. C. Prescott. "The Equity Premium: A Puzzle.” Journal of Monetary Economics, 15 (1985), 145-161.

Merton, R. C. "Optimum Consumption and Portfolio Rules in a Continuous-Time Model." Journal of Economic Theory, 3 (1971), 373-413.

Perold, A. F., and W. F. Sharpe. "Dynamic Strategies for Asset Allocation." Financial Analysts Journal, 44 (1988), 16-27.

Quah, J. K.-H. "The Law of Demand When Income Is Price Dependent." Econometrica, 65 (1997), 1421-1442.

Roll, R. "Evidence on the 'Growth-Optimum' Model.” Journal of Finance, 28 (1973), 551-566.

Rubinstein, M. "The Strong Case for the Generalized Logarithmic Utility Model as the Premier Model of Financial Markets." Journal of Finance, 31 (1976), 551-571.

Russell, T. "Portfolio Separation: The Analytic Case.” Economics Letters, 6 (1980), 59-66.

Samuelson, P. A. "Lifetime Portfolio Selection by Dynamic Stochastic Programming." Review of Economics and Statistics, 51 (1969), 239-246.

Spare, A., and P. Ciotti. Relative Dividend Yield: Common Stock Investing for Income and Appreciation. New York, NY: John Wiley \& Sons (1999).

Thorp, E. O. "Portfolio Choice and the Kelly Criterion." In Stochastic Models in Finance, W. T. Ziemba and R. G. Vickson, eds. New York, NY: Academic Press (1971).

Tobin, J. "Liquidity Preference as Behavior Towards Risk." Review of Economic Studies, 25 (1958), 65-86.

von Neumann, J., and O. Morgenstern. Theory of Games and Economic Behavior. Princeton, NJ: Princeton University Press (1944).

Welch, I., and A. Goyal. "A Comprehensive Look at the Empirical Performance of Equity Premium Prediction.” Review of Financial Studies, 21 (2008), 1455-1508.

Wolf, M. "Stock Returns and Dividend Yields Revisited: A New Way to Look at an Old Problem." Journal of Business and Economic Statistics, 18 (2000), 18-30.

Ziemba, W. T., and J. M. Mulvey. Worldwide Asset and Liability Modeling. Cambridge, UK: Cambridge University Press (1998). 